\title{
What You See Is Not What You Get: The Costs of Trading Market Anomalies
}

\author{
Andrew J. Patton \\ Duke University \\ Brian M. Weller \\ Duke University
}

October 24, 2017

ERID Working Paper Number 255

This paper can be downloaded without charge from the Social Science Research Network Electronic Paper Collection:

\author{
http://ssrn.com/abstract=3034796
}

\section{Economic Research Initiatives at Duke WORKING PAPERS SERIES}

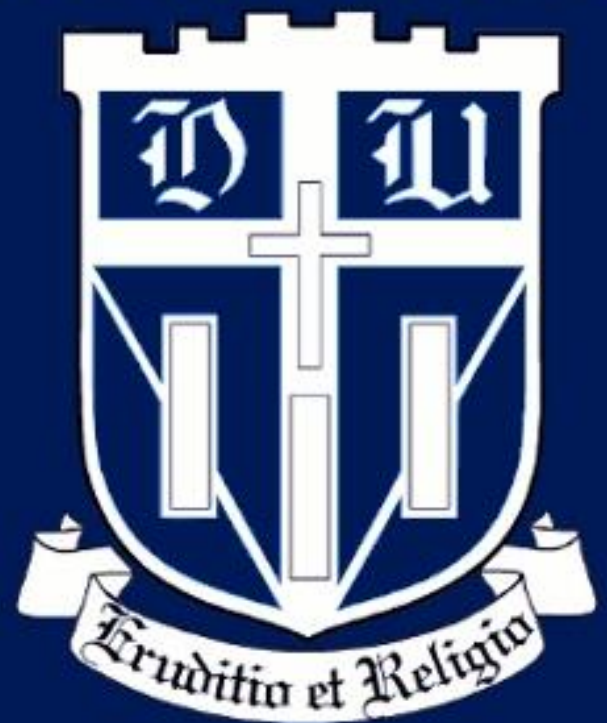




\title{
What You See is Not What You Get: The Costs of Trading Market Anomalies
}

\author{
Andrew J. Patton and Brian M. Weller* \\ Duke University
}

October 24, 2017

\begin{abstract}
Is there a gap between the profitability of a trading strategy "on paper" and that which can be achieved in practice? We answer this question by developing two new techniques to measure the real-world implementation costs of financial market anomalies. The first method extends Fama-MacBeth regressions to compare the on-paper returns to factor exposures with those achieved by mutual funds. The second method estimates average return differences between stocks and mutual funds matched on risk characteristics. Unlike existing approaches, these techniques deliver estimates of implementation costs without estimating parametric microstructure models from trading data or explicitly specifying factor trading strategies. After accounting for implementation costs, typical mutual funds earn low returns to value and no returns to momentum.
\end{abstract}

JEL: G12, G14, G23

Keywords: Trading Costs, Performance Evaluation, Mutual Funds, Market Efficiency

*Email: andrew.patton@duke.edu, brian.weller@duke.edu. We thank Alex Chinco, Campbell Harvey, David Hsieh, Robert Korajczyk, Toby Moskowitz, and seminar participants at the Yale Junior Finance Conference and Duke Fuqua for valuable comments and discussion. 


\section{Introduction}

Empirical asset pricing overflows with explanations for differences in average returns across securities. The proliferation of predictors distracts from bona fide market anomalies from which we might draw lessons about risks, preferences, and beliefs. Increasing computing power accelerates the rate of factor discovery and the urgency of separating empirical regularities from journalfriendly fictions. Recent calls to action by Harvey, Liu, and Zhu (2016), Harvey (2017), and Hou, Xue, and Zhang (2017) have focused on high false discovery rates and scurrilous academic practices. Fundamentally they question whether candidate factors are real, statistical accidents, or intentional deceptions.

We give on-paper trading strategies the benefit of the doubt and instead question whether these are actionable in practice, thereby representing true expected return factors or market anomalies. This line of inquiry originates with Fama (1970), who considers the role of transactions costs in defining market efficiency and departures therefrom. Despite nearly fifty years of subsequent research, accurately measuring real-world transactions costs for academic factors remains a formidable challenge. Existing approaches generally fall into two categories. The first category entails using proprietary trading data to analyze the transactions costs for a single firm (e.g., Keim and Madhavan (1997), Engle, Ferstenberg, and Russell (2012), and Frazzini, Israel, and Moskowitz (2015)). Although selected firms are almost by definition not representative of asset managers as a whole, such analyses provide an informative lower bound on the transactions costs of factor strategies. The second approach uses market-wide trading data such as NYSE Trade and Quote (TAQ) to estimate price impact functions for individual securities. These papers then accumulate simulated costs of trades implied by dynamic factor strategies (e.g., Lesmond, Schill, and Zhou (2004), Korajczyk and Sadka (2004), and Novy-Marx and Velikov (2016)). Papers in this camp either establish a lower bound on trading costs by dispensing with non-proportional costs of trade or estimate parametric price impact models and extrapolate trading costs beyond small portfolio sizes.

We introduce two new methodologies for measuring real-world implementation costs for factor trading strategies. Our approaches differ from existing methods in that they do not utilize specialized trading data or parameteric transaction cost models, nor do they require the user to take a stand on the exact form of factor trading strategies. This latter feature is particularly important because high-turnover academic factors like momentum may have industry variants with significantly lower implementation costs. Together these features facilitate the estimation of the all-in implementation costs for several academic factors and a representative population of asset managers.

Our first approach is an extension of the familiar Fama and MacBeth (1973) procedure. FamaMacBeth regressions estimate factor loadings $\beta_{i k}$ with time-series regressions for each test asset $i$ and each factor $k$, and then estimate the compensation per unit of factor exposure $\lambda_{k t}$ using cross-sectional regressions at each date $t$. Standard test assets are based on stock portfolios, and 
the resulting estimates of of factor exposure compensation, denoted $\lambda_{k t}^{S}$, represent the "on-paper" profitability of a given factor strategy. We augment the set of test assets to include all the set of all 7,320 U.S. domestic mutual funds, and we allow the compensation earned by mutual funds for the same exposure to a given factor $\lambda_{k t}^{M F}$ to differ from that which is available on paper. Unlike stock portfolio returns, (gross) mutual fund returns reflect the real-world implementation costs of factor strategies, thus the difference between mutual fund and stock portfolio compensation delivers an estimate of implementation costs for factor $k^{1,2}$ Because costs per unit of exposure are likely to be negatively correlated with factor exposures - funds that earn greater net returns to a factor are more likely to take greater exposures to it - our estimate of implementation costs represents a lower bound on the costs faced by a representative mutual fund.

The Fama-MacBeth approach described above compares slopes or incremental compensation for risk for stocks and mutual funds. Our second approach directly compares levels of compensation for stocks and mutual funds with similar risk characteristics. To make this comparison, we sort stocks into quintile portfolios based on characteristics, as in portfolio sorts or "high minus low" factor construction. Then, for each stock in quintile $q$ at date $t$, we construct a matched sample of mutual funds consisting of the three nearest mutual funds as assessed by Mahalanobis distance on factor betas. ${ }^{3}$ The difference in returns between stocks and matched mutual funds $\Delta_{k t}^{q}$ is our matched pairs estimate of implementation costs associated with real-world trading in beta-quintile $q$ of factor $k$ at date $t$. Because implementation costs are likely to be significantly higher on the short side of factor strategies, the difference in long-only returns $\Delta_{k t}^{5}$ delivers a lower bound on the implementation costs of a 5-1 long-short strategy for factor $k$.

Our empirical analysis focuses on the implementation costs of mutual funds for the market $(M K T),{ }^{4}$ value $(H M L)$, size $(S M B)$, and momentum $(U M D)$. We choose these factors because they comprise the dominant empirical models in academic finance (e.g., Fama and French (1992) and Carhart (1997)), and they serve as the basis for hundreds of billions of dollars in quantitatively managed assets. We study mutual funds as our set of asset managers because they collectively manage more than $\$ 16$ trillion of capital in the United States, ${ }^{5}$ and the mutual fund industry has been better populated for a longer period of time than alternative asset managers such as hedge funds. Our approaches are readily extended to other factors and other market participants, however.

\footnotetext{
${ }^{1}$ We use gross returns to focus on the efficiency of mutual funds' investing technology rather than on the distribution of rents between managers and investors embedded in net returns.

${ }^{2}$ Our more sophisticated approaches account for time- and cross-sectional variation in implementation costs, which we discuss further below.

${ }^{3}$ Betas for stocks and matched mutual funds do not perfectly coincide. We follow Abadie and Imbens (2006, 2011) to shift mutual fund returns by the compensation for a "local" difference in betas. Because this return-adjustment takes the form of a cross-sectional regression of returns on betas, our approach marries matched pairs techniques with traditional factor models.

${ }^{4}$ We use the CRSP value-weighted market portfolio net of the one-month Treasury bill rate as our zero-cost market factor proxy.

${ }^{5}$ Source: the 2017 Investment Company Fact Book, available at http://www.icifactbook.org/.
} 
Our analysis delivers three new empirical facts on the implementation costs of anomalies for typical mutual funds. First, momentum strategies suffer extreme underperformance in practice: our estimates of annual implementation costs are in the range of $2.2 \%-9.3 \%$, which eliminates most profits accruing to momentum during the 1970-2016 period. We conclude - as Lesmond, Schill, and Zhou (2004) do - that transactions costs make momentum strategies inaccessible to typical asset managers. Second, mutual fund implementation costs sharply reduce returns to the value factor, although our approaches differ on the extent of underperformance; the corresponding average annual differences between on-paper and mutual fund performance for value are $2.4 \%-5.1 \%$. By contrast, mutual funds implement market and size factor exposure relatively well compared to the academic benchmark, although they still underperform in capturing outsize returns to the smallsize characteristic. Third, average implementation costs are stationary despite secular declines in bid-ask spreads and commissions since 1970. Industry inflows increase transactions costs, which neutralize reductions in costs to the first dollar traded in factor strategies. This channel provides a non-proportional costs of trading rationale for Pastor and Stambaugh (2012)'s industry-level diseconomies of scale in asset management.

As a second empirical contribution, we focus on cross-sectional heterogeneity in implementation costs and demonstrate the importance of benchmarking performance and considering market efficiency as a function of investors' trading technology. While the typical firm's compensation for momentum is indistinguishable from zero, subsets of the mutual fund universe may achieve positive returns to momentum net of costs. A focused analysis on smaller market segments is important from an aggregate market efficiency perspective because a violation exists if the marginal investor sees anomalous profits, even if a typical investor does not. For this purpose we segment the mutualfund universe by (lagged) total net assets. Size is a natural sorting dimension because Berk and Green (2004), Pastor, Stambaugh, and Taylor (2015), Berk and van Binsbergen (2015), and others link scale to gross-of-fees performance. We rerun our cross-sectional analysis using each mutual fund size category separately, and we confirm that small and large mutual funds achieve different returns to momentum from "typical" mutual funds. Using this insight we reconcile conflicting evidence on the transactions-cost rationale for the continued existence of the momentum anomaly.

While our new approaches deliver simple, nonparametric, estimates of the implementation costs for factor trading strategies, they do face some limitations. Firstly, as mentioned above, both approaches deliver lower bounds on implementation costs. In our empirical analysis these bounds do not greatly limit the conclusions we can draw: the estimated costs are already so high as to eliminate or severely attenuate the on-paper profitability of strategies like value and momentum for typical mutual funds. For other strategies, estimates that indicate positive returns net of costs do not necessarily imply that an anomaly can be implemented by typical investors. In this sense our measures can diagnose an implementation problem with a factor, but they cannot deliver a clean bill of health. 
Secondly, our techniques rely on real-world asset managers to reveal implementation costs through realized returns to their chosen factor exposures. We require a subset of asset managers to invest in the factor of interest over an extended period of time. This requirement is not likely to be satisfied when studying a factor that is new to the academic literature and fund managers have not had an opportunity to trade on this factor.

Finally, like much of the literature on performance evaluation, our methods are susceptible to criticism of the choice of factors included in the analysis. A manager who is following a strategy that does not correspond to an approximate linear combination of those included in the model may appear to have high implementation costs for the included strategies, even though she has low costs for the strategy actually being implemented. Our methods speak only to implementation costs of the projection of traded strategies on the included factors.

Confronted with hundreds of cross-sectional return predictors, recent papers have proposed techniques to help focus attention on the most robust anomalies. ${ }^{6}$ Notwithstanding the limitations of our approach mentioned above, we recommend our methodologies as complements to these suggestions for three reasons. First, our methodologies provide an easy test of the real-world applicability of a conjectured factor. If mutual funds are not compensated for factor exposure, a factor is less likely to be real or implementable. We anticipate that our implementability test generalizes Hou, Xue, and Zhang (2017)'s suggestion to exclude microcap stocks in that strategies relying on the smallest stocks would see large real-world performance attrition relative to paper portfolios. Second, our approaches provide orthogonal information to existing asset pricing tests. While it might be possible to reconfigure empirical choices to elevate a $t$-statistic from 2 to 3 , we view it as less likely that an entirely new hurdle can be cleared for spurious factors. Third, the computational burden of our technique is low, and mutual fund performance data is readily available to empirical researchers. With our techniques the barriers to entry for cross-sectional asset pricing work are not appreciably raised.

\section{Related Literature}

The Fama and French three-factor model has been the benchmark for empirical asset pricing since its introduction in 1992. This empirical model supplanted the CAPM, but its new value and size factors had little theoretical motivation. ${ }^{7}$ As factors continued to emerge over the next quarter century - most notably, the momentum anomaly of Jegadeesh and Titman (1993) - several strands of literature emerged in an attempt to tame the "factor zoo" (Cochrane (2011)). One active strand investigates the implementation costs of anomalies with a particular focus on size,

\footnotetext{
${ }^{6}$ Harvey, Liu, and Zhu (2016) advocate raising statistical significance thresholds. Harvey (2017) endorses mixing standard thresholds with Bayesian priors on the plausibility of a factor. Giglio and Xiu (2017) suggest "cleaning" factors of noise using variation in test asset returns.

${ }^{7}$ Banz (1981) and Basu (1977) document price-earnings ratios and market capitalization as characteristics associated with deviations from the CAPM.
} 
value, and momentum anomalies. While transactions costs cannot explain why expected return discrepancies come to be in the first place, this literature (reviewed below) seeks to rationalize the continued existence of market anomalies as their byproduct. Our paper advances this line of inquiry by introducing a new and readily generalizable approach for measuring the real-world transactions costs of return factors and anomalies.

Existing methods for measuring implementation costs take two approaches. The first approach uses specialized trading data to evaluate the costs of trade for large investment managers with the implicit assumption that these managers are representative of sophisticated investment managers. These papers typically assess trading costs using Perold (1988)'s implementation shortfall measure, which captures the difference between realized profits and on-paper profits using a preset decision price. This approach dates back at least to Keim and Madhavan (1997), who analyze the transactions costs of a variety of investment styles for $\$ 83$ billion of trades. A key challenge to this method is that institutional trading is endogenous; traders are particularly aggressive in their trading targets when liquidity is readily available, which in turn imparts a downward bias to estimated cost functions. Frazzini, Israel, and Moskowitz (2015) overcome this challenge by using data from an investment manager whose trading targets are model-generated and selected irrespective of market conditions. Armed with more than $\$ 1$ trillion of trades, they analyze value, size, and momentum anomalies and find that all of them are implementable and scalable to tens or hundreds of billions of dollars of invested capital. By their reckoning, major anomalies continue to be anomalous if their asset manager's costs are representative of typical investment managers' costs.

The second approach trades off accuracy for representativeness in estimating transactions costs. Rather than using proprietary trading data for a single asset manager to estimate costs directly, other studies derive transactions costs using aggregate price and transaction records and extrapolate estimated price impact functions to factor trading strategies. ${ }^{8}$ Much of this literature focuses on the momentum anomaly because of its high turnover, and even the originating article establishing the momentum anomaly considers a trading-costs explanation (Jegadeesh and Titman (1993) and later Jegadeesh and Titman (2001)). Notably none of these papers use precise "all in" trading cost measures like implementation shortfall because theoretical or "decision-date" prices are not obtainable outside of specialized trading data.

Chen, Stanzl, and Watanabe (2002) estimate separate price impact functions for 5,173 individual stocks and calculate the trading costs accruing to size, value, and momentum strategies. The authors suggest that all factors have break-even carrying capacities on the order of millions of dollars $(H M L)$ to hundreds of millions of dollars $(S M B)$. By their calculations, factor strategies are not investable. Lesmond, Schill, and Zhou (2004) suggest that momentum trades in "disproportionately high cost securities" rather than the typical-transactions cost securities Jegadeesh and Titman (1993) use for approximating the costs of trading momentum. Using effective spreads from TAQ,

\footnotetext{
${ }^{8}$ Grundy and Martin (2001) and Barroso and Santa-Clara (2015) invert this logic and calculate the transactions costs that would be required to wipe out the momentum anomaly.
} 
commission schedules from a discount brokerage, and "all-in" frictions implied by zero-trading days (Lesmond, Ogden, and Trzcinka (1999)), Lesmond, Schill, and Zhou (2004) argue that trading costs erase the returns to the momentum anomaly.

Korajczyk and Sadka (2004) present more optimistic results on the investability of factor strategies. Korajczyk and Sadka (2004) estimate effective and quoted spreads and non-proportional trading costs functions of Glosten and Harris (1988) and Breen, Hodrick, and Korajczyk (2002) using TAQ data. In utilizing different non-proportional cost functions from Lesmond, Schill, and Zhou (2004), Korajczyk and Sadka (2004) extrapolate trade-level costs to find positive net-ofcost returns to the momentum anomaly. They invert their cost function estimates to obtain a break-even momentum strategy carrying capacity of $\$ 5$ billion. While much smaller than Frazzini, Israel, and Moskowitz (2015)'s estimates, these carrying capacities are also measured based on older data for which transactions costs are significantly higher (Lou and Sadka (2016)). NovyMarx and Velikov (2016) follows a similar approach, but they focus only on proportional costs to establish a lower bound. The authors measure trading costs using effective spreads recovered from Hasbrouck (2009)'s Bayesian Gibbs sampler and tally costs of trading size, value, and momentum strategies, among others. Although the paper focuses on performance evaluation, Novy-Marx and Velikov (2016) find a momentum strategy carrying capacity of $\$ 5$ billion (as in Korajczyk and Sadka (2004)), and they find size and value carrying capacities of $\$ 170$ billion and $\$ 50$ billion respectively (which are comparable to Frazzini, Israel, and Moskowitz (2015)'s estimates).

Our work complements the two existing approaches to measuring implementation costs with new cross-sectional techniques that combine the best elements of both. Like papers that utilize proprietary trading data, our estimates reflect the all-in costs of implementing factor strategies, and they apply equally well for past and modern market environments (for which Lesmond, Ogden, and Trzcinka (1999)'s zero-trading day measure fails). Like papers that estimate transaction cost functions using market data, our methodology captures representative practitioners of factor investing rather than single special investment managers. In contrast with both approaches, our methodologies facilitate the evaluation of implementation costs (1) without specifying the precise trades used to implement factor strategies and (2) for arbitrary subsets of the asset management universe trading universe. This latter feature allows us to examine asset manager size strata separately in Section VI. In so doing we reconcile the contrasting findings of Lesmond, Schill, and Zhou (2004) and Frazzini, Israel, and Moskowitz (2015) by finding no net-of-costs return to momentum for typical mutual funds, but positive net-of-costs returns to the marginal mutual fund investor.

In concurrent work, Arnott, Kalesnik, and Wu (2017) propose a method similar to our FamaMacBeth two-stage regressions. They argue, as we do, that mutual funds deliver much lower returns on value and momentum anomalies than on-paper factor counterparts might indicate. Our paper differs from theirs in four key respects. First, in our Fama-MacBeth approach we compare cross-sectional slopes of mutual fund and stock portfolio returns with respect to factor exposures, 
whereas Arnott, Kalesnik, and Wu (2017) compare mutual fund return slopes and on-paper timeseries return realizations. The latter comparison sheds little light on implementation costs because realized factor slopes and factor returns may have very different means, as they do for the market factor. Second, our procedures address the omitted variable bias resulting from comovement in factor realizations and liquidity costs. In particular, the mismatch between first- and secondstage Fama-MacBeth regressions and the Lasso approach to accommodating heterogeneity in firmrelevant liquidity proxies are new to the implementation cost conversation. Third, we develop an entirely new approach to measuring implementation costs based on matching stocks and mutual funds with similar attributes to mimic the performance of characteristic-based portfolios in practice, and this approach reveals important differences between the size factor and characteristic. Finally, we slice the cross section of mutual funds to reconcile previous work on implementation costs, and we connect our stationary implementation costs empirically to recent work on industry-level diseconomies of scale in institutional investing.

\section{Data}

Our data primarily come from the CRSP mutual fund and stock databases. Our mutual fund sample consists of 7,320 United States domestic equity mutual funds with at least 24 non-missing monthly gross returns during the period January 1970 to December 2016. Our stock sample, also monthly to match the mutual fund sample, consists of all CRSP stocks (share codes 10 or 11) for the corresponding period and subject to the same non-missing requirement, which gives a total of 22,121 unique PERMNOs.

Appendix A details our mutual fund filtering methodology. Therein we describe a number of data cleaning and filtering steps based on the recommendations of Berk and van Binsbergen (2015), Pastor, Stambaugh, and Taylor (2015), and others. One data processing step bears special mention here: we map funds delineated by share class into fund groups. Share classes for funds with identical investments differ in fees charged to investors, but they are not otherwise economically distinct. To aggregate returns within a fund group, we take total-net asset weighted gross-of-fee returns. CRSP provides returns net of management and $12 \mathrm{~b}$ fees, and we convert these into gross returns by adding expense ratios divided by 12, following Fama and French (2010).

Significant changes in the count of active mutual funds reflect both a secular growth in the mutual fund industry and continual improvements in data quality. ${ }^{9}$ Figure I highlights these changes by plotting the number of non-missing returns for domestic equity mutual funds by month. The number of funds increases from 292 in January 1970 to 1,135 in July 1993 to 3,893 in December 2016. Because the number and composition of funds varies widely over time, we conduct our analysis

\footnotetext{
${ }^{9}$ Pages 1-2 of the CRSP mutual fund database guide details the amalgamation of data sources used to construct returns from December 1961 through the present. Page 16 discusses the merge of classifications into CRSP objective or style codes that we use to restrict the set of funds to United States domestic equity funds.
} 
Figure I: Count of Active Domestic Equity Mutual Funds by Month

Figure plots the count of non-missing returns by month for United States domestic equity mutual funds. The dashed line at January 1970 marks the starting point of our 1970-2016 sample. The dashed line at July 1993 marks the midpoint of the post-1970 sample as well as the start date for our post-Jegadeesh and Titman (1993) sample.

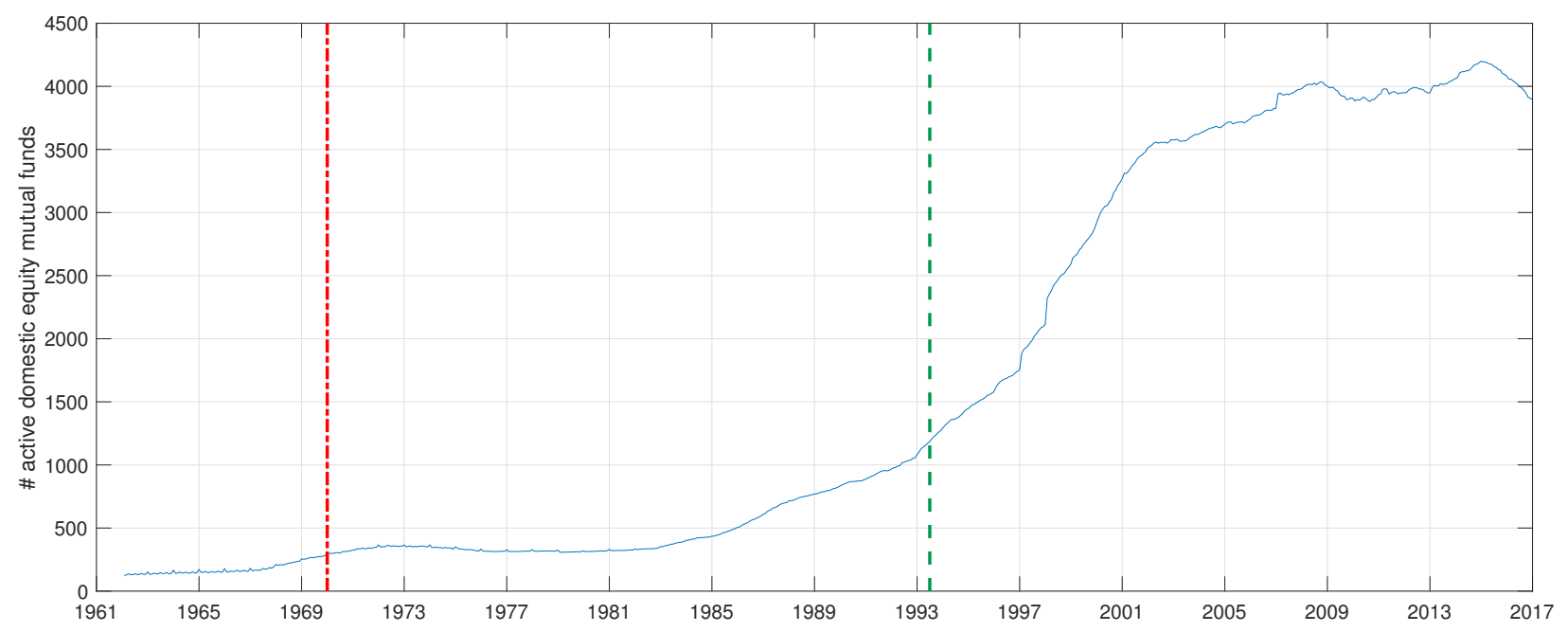

both on an extended sample and on a more recent subsample. Our long sample runs from January 1970 to December 2016. We discard the 1962-1969 window during which monthly returns are less consistently provided and during which several of our liquidity proxies are not available. Our recent subsample consists of the latter half of the long sample and runs from July 1993 to December 2016. This start date postdates Jegadeesh and Titman (1993)'s documenting of the momentum anomaly, the most recently discovered factor we consider. Table I reports summary statistics for the set of mutual funds used in our analysis. All told the 1970-2016 sample consists of 1,068,106 fund-month observations and the 1993-2016 sample consists of 926,824 fund-month observations.

Much of our analysis compares mutual funds with similar stocks as measured by loadings on equity risk factors. Our Fama-MacBeth tests of Section IV combine mutual fund data with common test portfolios. Because our factor set includes value (HML), size (SMB), and momentum (UMD), our baseline analysis uses the Fama-French 25 size-value double-sorted portfolios plus 25 sizebeta portfolios, 25 size-prior return portfolios, and 25 size-Amihud illiquidity portfolios to ensure adequate dispersion in loadings to identify risk premia in the cross section. We supplement this set of test assets with an expanded cross section following the recommendation of Lewellen, Nagel, and Shanken (2010). In our larger portfolio set, we also include 49 industry portfolios, 25 sizeoperating profitability portfolios, 25 size-investment portfolios, 10 beta-sorted portfolios, 10 market capitalization-sorted portfolios, 10 book equity to market equity ratio sorted portfolios, 10 Amihud illiquidity-sorted portfolios, 10 operating profitability-sorted portfolios, and 10 investment-sorted portfolios for a total of 269 portfolios. With the exception of the illiquidity-sorted portfolios, all 
Table I: Domestic Equity Mutual Fund Sample Summary Statistics

Table presents summary statistics for the 1970-2016 sample of 7,320 United States domestic equity mutual funds. The top subtable provides information on the time series of the number of active funds for each date as well as cross-sectional information on fund lifetimes and total net assets (TNA) at sample start, middle, and end. The bottom subtable reports distributional information on fund excess returns. $\bar{\rho}$ is the average pairwise correlation with other mutual funds' returns, and $\rho_{S \& P 500}$ is the correlation with the $\mathrm{S} \& \mathrm{P} 500$.

\begin{tabular}{|c|c|c|c|c|c|}
\hline Unit & $\begin{array}{l}\text { Funds } \\
\quad \#\end{array}$ & $\begin{array}{l}\text { Lifetime } \\
\text { Years }\end{array}$ & $\begin{array}{l}\text { TNA, Jan. } 1970 \\
\text { Million USD }\end{array}$ & $\begin{array}{l}\text { TNA, July } 1993 \\
\text { Million USD }\end{array}$ & $\begin{array}{l}\text { TNA, Dec. } 2016 \\
\text { Million USD }\end{array}$ \\
\hline Mean & 1894 & 12.16 & 176.77 & 1653.6 & 1551.1 \\
\hline Std. Dev. & 1552 & 9.00 & 781.22 & 25905 & 6858.5 \\
\hline $25 \%$ & 355 & 5.33 & 7.17 & 31.6 & 49.4 \\
\hline $50 \%$ & 1197 & 9.92 & 26.73 & 88.73 & 201.85 \\
\hline $75 \%$ & 3712 & 16.63 & 94.37 & 282.46 & 859.8 \\
\hline Unit & $\begin{array}{l}\text { Mean Return } \\
\% / \text { Month }\end{array}$ & $\begin{array}{l}\text { Return Vol. } \\
\% / \text { Month }\end{array}$ & $\begin{array}{c}\text { Sharpe Ratio } \\
\text { Annualized }\end{array}$ & $\begin{array}{c}\bar{\rho}_{M F} \\
\%\end{array}$ & $\begin{array}{c}\rho_{S \& P 500} \\
\%\end{array}$ \\
\hline Mean & 0.48 & 4.96 & 0.42 & 76.74 & 86.55 \\
\hline Std. Dev. & 0.62 & 1.88 & 0.42 & 16.32 & 18.19 \\
\hline $25 \%$ & 0.32 & 3.98 & 0.24 & 74.64 & 84.21 \\
\hline $50 \%$ & 0.59 & 4.71 & 0.44 & 80.37 & 91.13 \\
\hline $75 \%$ & 0.80 & 5.61 & 0.61 & 84.49 & 95.26 \\
\hline
\end{tabular}

portfolio data are downloaded from Ken French's website. Decile illiquidity portfolios sort by monthly averages of non-missing daily absolute returns over dollar volume, and stocks are assigned for the following year using deciles the end of June, by parallel with the timing convention of the other portfolio data. The 25 size-illiquidity portfolios sort on both lagged market capitalization and Amihud illiquidity quintile. Our analysis uses both equal- and value-weighted stock portfolios.

We include several market and funding liquidity variables to proxy for time-varying cost factors that may affect the performance of mutual funds relative to stocks. Our market liquidity variables are Amihud illiquidity (Amihud (2002)), Pastor-Stambaugh liquidity levels (Pastor and Stambaugh (2003)), Corwin and Schultz (2012) NYSE-average bid-ask spreads, and the CBOE S\&P 500 Volatility Index (VIX), as motivated by Nagel (2012). We use Corwin and Schultz (2012)'s methodology to estimate bid-ask spreads because it enables measurement of market liquidity before TAQ becomes available in 1993 and because it captures average effective spread levels and innovations better than other pre-TAQ methodologies (see Corwin and Schultz (2012) Table IV). ${ }^{10}$

\footnotetext{
${ }^{10}$ Corwin and Schultz make their code available at https://www3.nd.edu/ scorwin/HILOW_Estimator_Sample_002.sas. As in their paper, we compute cross-sectional averages using only NYSE-listed stocks, and we use their variant of
} 
We use the CBOE S\&P 100 Volatility Index (VXO) in place of the VIX in the pre-1990 period for which the VIX is not available. We compute Amihud illiquidity using CRSP daily data with values averaged within a month as in Amihud (2002), and we obtain the Pastor-Stambaugh series and CBOE VXO/VIX series from Robert Stambaugh's website and the Federal Reserve of St. Louis's FRED database, respectively.

Our funding liquidity variables are Frazzini and Pedersen (2014)'s "betting against beta" (BAB) factor, He, Kelly, and Manela (2017)'s intermediary capital ratio, the 10-year BAA minus 10-year Treasury spread, and the 3-month LIBOR minus 3-month Treasury yield or "TED" spread. The first two series are expressly designed to capture institutions' funding liquidity constraints, and the latter two series are common proxies in the funding liquidity literature (e.g., Brunnermeier (2009)). We obtain BAB from AQR's website, intermediary capital ratios from Asaf Manela's website, and credit and TED spreads from FRED.

\section{Fama-MacBeth Estimates of Implementation Costs}

We measure the returns to factor investing using two approaches. In this section we consider the compensation per unit of risk exposure and investigate whether mutual funds obtain the same risk premium that academics achieve on paper. In the next section we evaluate the gross-of-fee returns to investing in factor portfolios of stocks and mutual funds with similar risk attributes.

\section{A. Baseline Estimates}

In our baseline estimation, we assume that mutual funds have a constant per-unit cost for implementing academic anomalies. Investing in a market index with $\beta_{M K T}=1$ results in a performance gap of $\eta$ relative to the on-paper performance of a market index, and investing in a levered version of the market more generally results in a performance gap of $\eta \beta_{M K T}$. In this setting, we would expect performance differences between stock and mutual fund portfolios to be linear in factor exposure.

We estimate the "implementation gap" using augmented Fama and MacBeth (1973) two-stage regressions for the Carhart four-factor model (Carhart (1997)). The time-series regression step is standard except for the choice of test assets. As discussed in the preceding section, our sorting characteristics pertain to each factor in $f_{k t}$, and we have $N_{S}=100$ and $N_{S}=269$ stock portfolios depending on regression specification. In addition to stock portfolios, we also include as test assets $N_{M F}=7,320$ mutual funds, of which several thousand are active in the typical period. As diversified entities spanning a wide range of multifactor risk exposures, mutual funds unlike stocks need not be grouped into portfolios via a characteristic-sorting procedure.

The $N_{S}+N_{M F}$ time-series regressions are

estimated spreads in which negative values are set to 0. 


$$
r_{i t}=\alpha_{i}+\sum_{k} f_{k t} \beta_{i k}+\epsilon_{i t}, i=1, \ldots, N_{S}, N_{S+1}, \ldots, N_{S}+N_{M F},
$$

where $r_{i t}$ is the month $t$ gross return on stock portfolio or mutual fund $i$ net of the contemporaneous risk-free rate and $f_{k t}$ (for $k=1, \ldots, K$ ) is the return on factor $k$ at date $t$. The usual second-stage cross-sectional regressions are extended to accommodate the possibility of differences in risk pricing for stocks and mutual funds,

$$
r_{i t}=\sum_{k} \lambda_{k t}^{S} \hat{\beta}_{i k} 1_{i \in S}+\sum_{k} \lambda_{k t}^{M F} \hat{\beta}_{i k} 1_{i \in M F}+\epsilon_{i t}, t=1, \ldots, T
$$

$\lambda_{k t}^{S}$ is the realized price of risk for factor $k$ and date $t$ based on stock returns, and $\lambda_{k t}^{M F}$ is the corresponding estimate based on mutual fund returns. ${ }^{11}$ The difference $\hat{\lambda}_{k t}^{\Delta} \equiv \hat{\lambda}_{k t}^{S}-\hat{\lambda}_{k t}^{M F}$ is our estimate of the implementation costs for strategy $k$ : it is the difference between the on-paper profitability of a given strategy ("what you see") and the actual returns achieved by an asset manager facing real-world implementation costs ("what you get"). Conceptually this difference captures both direct costs such as spreads and price impact from factor trading as well as indirect costs such as investing in liquid versions of factors to robustify strategies against outflows. ${ }^{12}$ Our point estimates are the average of the monthly differences in factor compensation $\bar{\lambda}_{k}^{\Delta}$, and we construct standard errors for this difference using Newey and West (1987) with three monthly lags to account for serial correlation and heteroskedasticity in the $\lambda$-difference series.

Throughout our analysis, we estimate cross-sectional slopes of returns on risk exposures assuming that risk exposures are constant. In making this assumption we prioritize minimizing the errors-in-variables problem arising from using noisy betas as inputs in the second-stage FamaMacBeth regression. This problem is vitally important because we do not want to find differences in $\lambda$ s simply as a byproduct of higher measurement error in mutual fund betas. However, in using long estimation windows to estimate $\beta$ s, we nonetheless take on potential measurement error arising from time-variation in stock portfolio or mutual fund risk exposures.

Following Lettau, Maggiori, and Weber (2014) and others, we omit the constant term to force cross-sectional average alphas to zero. Economically this omission forces the typical zero-risk security or mutual fund to have zero excess (gross) return at each point in time. We impose this restriction because the slope on $\beta_{M K T}$ is not otherwise well identified in our stock portfolio sample, namely the time series of the intercept $\alpha_{t}$ and the estimated market risk premium $\lambda_{M K T, t}$ are strongly negatively correlated and of similar magnitudes. By contrast in the mutual fund sample, $\hat{\beta}_{i k}$ has a large and positive risk price regardless of whether a constant is included. None of the

\footnotetext{
${ }^{11}$ Because the indicators partition the set of observations, Regression (2) is equivalent to two separate cross-sectional regressions run on stocks and mutual funds.

${ }^{12}$ Julian Robertson's Tiger Management, one of the world's largest hedge funds in the late 1990s, collapsed precisely because it could not continue to service outflows associated with its value investment strategy. Shleifer and Vishny (1997) formalize the role of agency frictions in perpetuating anomalies.
} 
other factor risk premia are meaningfully affected.

Table II presents estimates of Equation (2). The $\lambda^{\Delta}$ value in the upper-left corner indicates that the difference in compensation per unit of market exposure is $0.22 \%$ per year greater for risk exposures taken in practice via mutual funds than on paper in (100 equal-weighted) stock portfolios. This difference changes sign to favor on-paper portfolios by $0.38 \%$ per year when assessed against the full set of 269 portfolios because the average compensation for market beta is higher in the larger sample. Neither effect is statistically or economically significant, and the absence of a performance gap is robust to using value-weighted portfolios (bottom panel) rather than equalweighted portfolios. This result is unsurprising as mutual funds are expected to be relatively good at implementing the market factor.

Broadening our focus to columns 1-4, we see that mutual funds underperform stocks in isolating factor exposures for two of the other Carhart factors. The average implementation gaps for value $(H M L)$ and momentum $(U M D)$ range from of $54 \%-96 \%$ of the total on-paper return to each factor in stock portfolios. The remaining compensation to mutual funds for $H M L$ and $U M D$ are positive $\left(\lambda^{M F}>0\right)$, but they are only $1 \%-3 \%$ per year and marginally statistically significant for value and not statistically distinguishable from zero for momentum. Conversely, $H M L$ and $U M D$ factors are both highly compensated and statistically robust in equal-weighted paper portfolios in this period. Compensation for size factor $(S M B)$ exposure has a small positive point estimate for mutual funds, but these values are not reliably different from zero or from on-paper compensation for size.

Notably the point estimates for the differences $\lambda^{\Delta}$ for $H M L$ and $U M D$ are typically more statistically significant than either of the components of the difference $\lambda^{S}$ or $\lambda^{M F}$. This feature reflects the netting out of common variation in factor realizations within each cross section. Ideally the residual variation in $\lambda^{\Delta}$ captures only random variation in trading costs. In practice this residual variation also captures idiosyncratic differences in estimated risk prices associated with using different sets of test assets; the difference between $\lambda^{\Delta}$ estimated from the set of 100 stock portfolios and the set of 269 stock portfolios suggests that the implementation gap depends in part on the stock benchmarks employed.

Columns 5-8 reproduce these tests for the July 1993 to December 2016 sample. Mutual funds achieve lower returns to $H M L$ and $U M D$ and higher returns to $S M B$ than in the full sample, but these returns are now universally statistically indistinguishable from zero (in part because the sample length is cut in half). For stock portfolios, the compensation for $H M L$ and $U M D(S M B)$ exposures also decrease (increase) relative to the full sample. The net effect of these changes is a small decrease in the typical implementation gap for $H M L$ and a moderate decrease in the implementation gap for $U M D$. The implementation gap is roughly unchanged for market exposure (effectively zero) and $S M B$ exposure (positive but insignificant). In sum, focusing on the latter sample with a more broadly representative set of mutual funds does not change our conclusions 
Table II: Implementation Cost Estimates in Fama-MacBeth Regressions - Baseline Specification

Table reports Fama-MacBeth estimates of the compensation for factor exposure for stock portfolios (second panel), domestic equity mutual funds (third panel), and their difference (top panel). Coefficients are the average cross-sectional slopes $\bar{\lambda}_{k}$ across monthly regressions of excess returns $r_{i t}$ on time-series betas $\hat{\beta}_{i k}$,

$$
r_{i t}=\sum_{k} \lambda_{k t}^{S} \hat{\beta}_{i k} 1_{i \in S}+\sum_{k} \lambda_{k t}^{M F} \hat{\beta}_{i k} 1_{i \in M F}+\epsilon_{i t}, t=1, \ldots, T
$$

where $k$ indexes the four Carhart (1997) factors and $\lambda^{\Delta}$ is defined as $\lambda^{S}-\lambda^{M F}$. Stock portfolio sets are described in Section III. All coefficients are annualized and reported in percent. Standard errors are Newey-West with three lags. $t$ statistics are reported in parentheses.

(a) Equal-Weighted Stock Portfolios

\begin{tabular}{cccccccccc}
\hline & & \multicolumn{3}{c}{$\mathbf{1 9 7 0}-\mathbf{2 0 1 6}$} & & \multicolumn{3}{c}{$\mathbf{1 9 9 3}-\mathbf{2 0 1 6}$} \\
& $N_{S}$ & $M K T$ & $H M L$ & $S M B$ & $U M D$ & $M K T$ & $H M L$ & $S M B$ & $U M D$ \\
\hline \hline$\lambda^{\Delta}$ & 100 & -0.22 & $4.92^{* * *}$ & 1.52 & $7.62^{* * *}$ & -0.10 & $4.34^{* * *}$ & 1.93 & $4.68^{* * *}$ \\
$t$-stat & & $(-0.44)$ & $(5.54)$ & $(1.50)$ & $(5.17)$ & $(-0.15)$ & $(4.41)$ & $(1.40)$ & $(3.00)$ \\
$\lambda^{\Delta}$ & 269 & 0.38 & $3.33^{* * *}$ & 1.66 & $8.93^{* * *}$ & 0.89 & $2.47^{* *}$ & 2.04 & $6.71^{* * *}$ \\
$t$-stat & & $(0.76)$ & $(3.46)$ & $(1.52)$ & $(6.11)$ & $(1.35)$ & $(2.37)$ & $(1.37)$ & $(3.83)$ \\
\hline$\lambda^{S}$ & 100 & $6.72^{* * *}$ & $7.76^{* * *}$ & 2.99 & $9.48^{* * *}$ & $7.70^{* *}$ & $6.57^{* *}$ & 4.12 & 6.18 \\
$t$-stat & & $(2.77)$ & $(4.25)$ & $(1.53)$ & $(3.95)$ & $(2.32)$ & $(2.42)$ & $(1.48)$ & $(1.63)$ \\
$\lambda^{S}$ & 269 & $7.31^{* * *}$ & $6.17^{* * *}$ & 3.13 & $10.80^{* * *}$ & $8.69^{* * *}$ & 4.69 & 4.23 & 8.21 \\
$t$-stat & & $(3.04)$ & $(3.15)$ & $(1.52)$ & $(4.41)$ & $(2.65)$ & $(1.61)$ & $(1.45)$ & $(2.10)$ \\
\hline$\lambda^{M F}$ & - & $6.93^{* * *}$ & $2.84^{*}$ & 1.47 & 1.86 & $7.80^{* *}$ & 2.22 & 2.19 & 1.50 \\
$t$-stat & & $(2.85)$ & $(1.66)$ & $(0.83)$ & $(0.75)$ & $(2.39)$ & $(0.81)$ & $(0.92)$ & $(0.40)$ \\
\hline$T$ & & 564 & 564 & 564 & 564 & 282 & 282 & 282 & 282 \\
$\bar{N}_{M F}$ & 1894 & 1894 & 1894 & 1894 & 3290 & 3290 & 3290 & 3290 \\
\hline${ }^{*} p<.10,{ }^{* *} p<.05,{ }^{* * *}$ & $p<.01$ & & & & & &
\end{tabular}

(b) Value-Weighted Stock Portfolios

\begin{tabular}{|c|c|c|c|c|c|c|c|c|c|}
\hline & \multirow[b]{2}{*}{$N_{S}$} & \multicolumn{4}{|c|}{$1970-2016$} & \multicolumn{4}{|c|}{$1993-2016$} \\
\hline & & $M K T$ & $H M L$ & $S M B$ & $U M D$ & $M K T$ & $H M L$ & $S M B$ & $U M D$ \\
\hline$\overline{\overline{\lambda^{\Delta}}}$ & 100 & -0.31 & $4.22^{* * *}$ & -0.53 & $7.36^{* * *}$ & -0.36 & $3.96^{\text {*** }}$ & -0.30 & $4.46^{\text {*** }}$ \\
\hline$t$-stat & & $(-0.97)$ & $(5.09)$ & $(-0.71)$ & $(5.16)$ & $(-0.91)$ & $(4.61)$ & $(-0.32)$ & $(2.95)$ \\
\hline$\lambda^{\Delta}$ & 269 & -0.15 & $2.62^{* * *}$ & -0.70 & $7.27^{* * *}$ & 0.19 & $2.39^{* * *}$ & -1.02 & $5.17^{* * *}$ \\
\hline$t$-stat & & $(-0.61)$ & $(3.72)$ & $(-1.11)$ & $(5.31)$ & $(0.83)$ & $(3.65)$ & $(-1.31)$ & $(3.21)$ \\
\hline$\lambda^{S}$ & 100 & $6.62^{* * *}$ & $7.06^{* * *}$ & 0.94 & $9.23^{* * *}$ & $7.43^{* *}$ & $6.18^{* *}$ & 1.89 & 5.96 \\
\hline$t$-stat & & $(2.75)$ & $(3.81)$ & $(0.55)$ & $(3.90)$ & $(2.27)$ & $(2.20)$ & $(0.77)$ & (1.58) \\
\hline$\lambda^{S}$ & 269 & $6.78^{* * *}$ & $5.46^{* * *}$ & 0.77 & $9.14^{* * *}$ & $7.99^{* *}$ & 4.61 & 1.18 & $6.67^{*}$ \\
\hline$t$-stat & & $(2.83)$ & $(2.98)$ & $(0.45)$ & $(3.91)$ & $(2.46)$ & $(1.62)$ & $(0.49)$ & $(1.80)$ \\
\hline$\overline{\lambda^{M F}}$ & - & $6.93^{* * *}$ & $2.84^{*}$ & 1.47 & 1.86 & $7.80^{* *}$ & 2.22 & 2.19 & 1.50 \\
\hline$t$-stat & & $(2.85)$ & (1.66) & $(0.83)$ & $(0.75)$ & $(2.39)$ & $(0.81)$ & $(0.92)$ & $(0.40)$ \\
\hline $\bar{T}$ & & 564 & 564 & 564 & 564 & 282 & 282 & 282 & 282 \\
\hline $\bar{N}_{M F}$ & & 1894 & 1894 & 1894 & 1894 & 3290 & 3290 & 3290 & 3290 \\
\hline
\end{tabular}


on the high real-world efficacy of implementing market exposure and size and the low real-world efficacy of implementing value and momentum.

\section{B. Time- and Mutual-Fund Varying Per-Unit Cost Estimates}

Time-varying implementation costs complicate the comparison of compensation per unit of factor risk. To see why, consider the following augmented model of mutual fund costs. As before, let there be a set of academic factors $f$, where $f_{t}$ is a $1 \times K$ vector. Each mutual fund $i$ implements its favored version of academic factors and earns a return of

$$
h_{i t}=f_{t}-\eta_{i t},
$$

where $\eta_{i t}$ reflects tilts away from the academic factor on account of trading costs or factor optimization. This section differs from the previous one in that we no longer assume that $\eta$ is constant across funds and time. The $\eta_{i t}$ term in turn has components

$$
\eta_{i t}=\eta_{i}+\eta_{t} \gamma_{i}+\tilde{\eta}_{i t}
$$

The first component is the fixed, firm-specific cost of trading a factor. The second component is the set of $L$ time-varying liquidity costs $\eta_{t}$ multiplied by the $L \times K$ loadings of all factors on these liquidity $\operatorname{costs} \gamma_{i}$. Finally, $\tilde{\eta}_{i t}$ is a $1 \times K$ set of idiosyncratic costs, e.g., a surprise liquidity demand shock that thwarts or facilitates firm $i$ 's trading strategy for factor $k$.

Funds trade and earn returns

$$
r_{i t}=\alpha_{i}+h_{i t} \beta_{i}+\epsilon_{i t}=\left(\alpha_{i}-\eta_{i} \beta_{i}\right)+\left(f_{t}-\eta_{t} \gamma_{i}\right) \beta_{i}+\left(\epsilon_{i t}-\tilde{\eta}_{i t} \beta_{i}\right)
$$

An ideal test compares the average compensation $f_{t}$ for factor exposure for on-paper investment in stocks against the compensation $h_{i t}$ for factor exposure for real-world investment through investment managers. In the constant-cost setting of Section IV.A, we achieve this ideal: $\eta_{i t}$ simplifies to $\eta$, and Fama-MacBeth regressions with a $K$-factor model recovers consistent estimates of $f-h$ as in Equation (2).

By contrast, in this general setting we face two key challenges that complicate the straightforward comparison of $f_{t}$ and $h_{i t}$. First, trading costs vary over time, and these costs may covary with factor realizations. For example, several measures of funding and market liquidity deteriorate significantly during the 2007-2008 Financial Crisis, and the aggregate market return likewise is consistently negative at that time. Omitting relevant liquidity factors thus contributes to an omitted variable bias in time-series estimates of $\beta_{i}$ for investment managers, which in turn potentially invalidates simple comparisons of second-stage slope estimates. Second, investment managers select their risk exposures endogenously. An investor who has discovered improvements upon academic 
factors or is particularly skilled at trading a given factor cost-effectively is more likely to select a larger factor exposure, all else equal. For this reason we would expect mutual fund-specific trading gains $\eta_{i}$ to be increasing in $\beta_{i}$, and the cross-sectional slopes of returns with respect to $\beta_{i}$ are biased upward $\left(\hat{\lambda}_{t}^{M F}>\lambda_{t}^{M F}\right)$.

We now address these two sources of bias. To address the omission of trading cost factors, we assume that trading costs or optimization gains for mutual funds are spanned by liquidity proxies considered in the literature and discussed in Section III. Throughout we use liquidity levels rather than innovations because high illiquidity rather than increases in illiquidity relative to the previous month likely contribute to high factor implementation costs. ${ }^{13}$ We then run Fama-MacBeth regressions as before, but we extend the factor model to include liquidity proxies in the time-series regressions,

$$
r_{i t}=\alpha_{i}+\sum_{k} f_{k t} \beta_{i k}+\sum_{l} \tilde{\eta}_{l t} \tilde{\gamma}_{i l}+\epsilon_{i t}, i=1, \ldots, N_{S}, N_{S+1}, \ldots, N_{S}+N_{M F}
$$

where $\tilde{\eta}_{l t}$ are the liquidity factor proxies at time $t$. To avoid overfitting in the first stage by including too many correlated liquidity proxies, we start with two: the first principal component of four market liquidity variables (Amihud illiquidity, Pastor-Stambaugh liquidity, Corwin-Schultz bid-ask spreads and the CBOE VIX/VXO) and the first principal component of four funding liquidity variables (Frazzini and Pedersen (2014)'s "betting against beta" factor, He, Kelly, and Manela (2017)'s intermediary capital risk factor, 10-year BAA minus 10-year Treasury spreads, and 3-month LIBOR minus 3-month Treasury yield or "TED" spreads). We normalize all liquidity variables to have unit standard deviation before taking principal components because liquidity proxies vary widely in their scales. ${ }^{14}$

The second-stage cross-sectional regressions are exactly as in Equation (2). The mismatch in model specification for the time-series and cross-sectional regressions is intentional. In the timeseries regressions, we recover fund exposures to the academic factors, and we need the additional liquidity proxy variables to cleanse the estimated mutual fund factor loadings of omitted illiquidity components. By contrast, in the second stage, we recover the cost per unit exposure to the academic factors and do not want to include the liquidity proxy exposures. Excluding the liquidity factors

\footnotetext{
${ }^{13} \mathrm{By}$ contrast, if we sought to explain returns, innovations to liquidity expectations would be the correct variable to use (as emphasized by Pastor and Stambaugh (2003) and He, Kelly, and Manela (2017), among others).

${ }^{14}$ The CBOE VXO and the TED spread series start in January 1986. Our principal components procedure accommodates the missing liquidity proxy data using MATLAB's alternating least squares (ALS) algorithm. ALS extracts factors and completes missing data by conjecturing principal components and iteratively estimating principal component loadings $\phi$ and factor values $g$ until the distance between known and fitted values achieves a local minimum. We run PCA-ALS from 1,000 starting points and select the global distance-minimizing factors and loadings. By construction illiquidity principal components have unit standard deviation, and we assign these components an illiquidity interpretation by normalizing them to be positively correlated with the VIX/VXO.
} 
only in the second stage delivers $\hat{\lambda}_{t}^{S}=\lambda_{t}^{S}$ and

$$
\hat{\lambda}_{t}^{\Delta}=\lambda_{t}^{S}-\frac{\operatorname{cov}\left(r_{i t}^{M F}, \beta_{i}\right)}{\operatorname{var}\left(\beta_{i}\right)}=-\frac{\operatorname{cov}\left(\alpha_{i}-\eta_{i t} \beta_{i}, \beta_{i}\right)}{\operatorname{var}\left(\beta_{i}\right)}=\bar{\eta}_{t}+\frac{\operatorname{cov}\left(\left(\eta_{i t}-\bar{\eta}_{t}\right) \beta_{i}, \beta_{i}\right)}{\operatorname{var}\left(\beta_{i}\right)} .
$$

The final equality makes the standard assumption that alphas and betas are cross-sectionally uncorrelated. $\bar{\eta}_{t}$ represents the cross-sectional average per-unit liquidity costs to implementing the factor. The second term is the covariance between deviations from the average costs and $\beta$ s. Funds with a particular skill in investing in a factor likely have higher exposures to it - $\beta_{i}$ are endogenous - so $\eta_{i t}-\bar{\eta}_{t}$ will be low when $\beta_{i}$ is high, and the covariance will be negative. ${ }^{15}$ Consequently $\lambda_{k t}^{M F}$ is an upper bound on the realizable gains to factor investing per unit risk exposure, and $\lambda_{k t}^{\Delta}$ is a lower bound on the costs of implementing a factor strategy.

Table III reports results using the liquidity-extended first-stage regression. Results are virtually the same as those of the baseline specification in Table II with one exception. Mutual funds' (already low) compensation for $U M D$ exposure decreases from 1.80 to 1.47 in the long sample and from 1.50 to 0.43 in the recent sample, suggesting that liquidity risk exposure at least partly explains mutual funds' compensation for momentum. This finding extends one result of Asness, Moskowitz, and Pedersen (2013) to the universe of mutual funds. Asness, Moskowitz, and Pedersen (2013) find that momentum loads positively on liquidity risk, and we find that the same holds for mutual funds' implementation of momentum. We examine this feature in detail in Section VI.B.

Ideally we would use all liquidity variables rather than their principle components because we want to time-varying determinants of $\eta_{i t}$ to lie in the span of the liquidity-augmented factor model. Including more covariates increases the likelihood that we span $\eta_{i t}$ by including all salient liquidity proxies. At the same time, including additional highly correlated cost proxies may overfit the first-stage regression and deliver nonsensical cross-sectional slopes in Equation (2).

Sparse regression techniques offer a solution to this challenge. We replace the standard firststage regression with a Lasso or $l_{1}$-penalized regression (Tibshirani (1994)). The least-squared minimization problem of Equation (6) adds an additional term penalizing the liquidity coefficients,

$$
\min _{\beta, \tilde{\gamma}} \frac{1}{T_{i}} \sum_{t}\left(r_{i t}-\sum_{k} f_{k t} \beta_{i k}-\sum_{l} \tilde{\eta}_{l t} \tilde{\gamma}_{i l}\right)^{2}+\kappa\left(\sum_{k}\left|\beta_{i k}\right|+\sum_{l}\left|\tilde{\gamma}_{i l}\right|\right),
$$

where $\kappa$ represents a penalty term for coefficients different from zero. The problem reduces to least squares when $\kappa=0$; otherwise, liquidity coefficients are compressed toward zero. Note that we do not require a penalization in the cross-sectional step because the second-stage regression omits liquidity proxies. As before, we normalize all liquidity proxies to give them similar scales and an equal chance of entering the Lasso regression. We interpolate missing elements of the VXO/TED

\footnotetext{
${ }^{15}$ Including liquidity proxies in the second-stage introduces a more opaque omitted variable bias, as we discuss in Appendix B.
} 
Table III: Implementation Cost Estimates in Fama-MacBeth Regressions — Liquidity PCs

Table reports Fama-MacBeth estimates of the compensation for factor exposure for stock portfolios (second panel), domestic equity mutual funds (third panel), and their difference (top panel). Coefficients are the average cross-sectional slopes $\bar{\lambda}_{k}$ across monthly regressions of excess returns $r_{i t}$ on time-series betas $\hat{\beta}_{i k}$,

$$
r_{i t}=\sum_{k} \lambda_{k t}^{S} \hat{\beta}_{i k} 1_{i \in S}+\sum_{k} \lambda_{k t}^{M F} \hat{\beta}_{i k} 1_{i \in M F}+\epsilon_{i t}, t=1, \ldots, T
$$

where $k$ indexes the four Carhart (1997) factors and $\lambda^{\Delta}$ is defined as $\lambda^{S}-\lambda^{M F}$. First-stage regression estimates include these factors, the first principal component of market liquidity proxies, and the first principal component of funding liquidity proxies. Liquidity proxies and stock portfolio sets are described in Section III. All coefficients are annualized and reported in percent. Standard errors are Newey-West with three lags. $t$ statistics are reported in parentheses.

(a) Equal-Weighted Stock Portfolios

\begin{tabular}{|c|c|c|c|c|c|c|c|c|c|}
\hline & \multirow[b]{2}{*}{$N_{S}$} & \multicolumn{4}{|c|}{$1970-2016$} & \multicolumn{4}{|c|}{$1993-2016$} \\
\hline & & $M K T$ & $H M L$ & $S M B$ & $U M D$ & $M K T$ & $H M L$ & $S M B$ & $U M D$ \\
\hline$\overline{\overline{\lambda^{\Delta}}}$ & 100 & -0.38 & $5.26^{* * *}$ & $1.80^{*}$ & $8.01^{* * *}$ & -0.04 & $4.06^{* * *}$ & 1.98 & $5.41^{* * *}$ \\
\hline$t$-stat & & $(-0.79)$ & $(5.89)$ & $(1.76)$ & $(5.38)$ & $(-0.06)$ & $(3.93)$ & $(1.47)$ & $(3.15)$ \\
\hline$\lambda^{\Delta}$ & 269 & 0.20 & $3.84^{* * *}$ & $2.03^{*}$ & $9.24^{* * *}$ & 0.80 & $2.51^{* *}$ & 2.22 & $6.84^{* * *}$ \\
\hline$t$-stat & & $(0.40)$ & $(3.89)$ & $(1.85)$ & $(6.16)$ & (1.19) & $(2.33)$ & $(1.55)$ & $(3.61)$ \\
\hline$\overline{\lambda^{S}}$ & 100 & $6.55^{* * *}$ & $8.06^{* * *}$ & $3.22^{*}$ & $9.49^{* * *}$ & $7.77^{* *}$ & $5.97^{* *}$ & 4.22 & 5.84 \\
\hline$t$-stat & & $(2.71)$ & $(4.34)$ & $(1.67)$ & $(3.97)$ & $(2.35)$ & $(2.20)$ & $(1.54)$ & $(1.54)$ \\
\hline$\lambda^{S}$ & 269 & $7.13^{* * *}$ & $6.64^{* * *}$ & $3.45^{*}$ & $10.71^{* * *}$ & $8.61^{* * *}$ & 4.42 & 4.46 & $7.26^{*}$ \\
\hline$t$-stat & & $(2.99)$ & $(3.31)$ & $(1.69)$ & $(4.38)$ & $(2.65)$ & $(1.50)$ & $(1.57)$ & $(1.85)$ \\
\hline$\overline{\lambda^{M F}}$ & - & $6.93^{* * *}$ & 2.80 & 1.42 & 1.47 & $7.82^{* *}$ & 1.91 & 2.24 & 0.43 \\
\hline$t$-stat & & $(2.86)$ & (1.63) & $(0.79)$ & $(0.60)$ & $(2.41)$ & $(0.69)$ & $(0.93)$ & $(0.11)$ \\
\hline $\bar{T}$ & & 564 & 564 & 564 & 564 & 282 & 282 & 282 & 282 \\
\hline $\bar{N}_{M F}$ & & 1894 & 1894 & 1894 & 1894 & 3290 & 3290 & 3290 & 3290 \\
\hline
\end{tabular}

(b) Value-Weighted Stock Portfolios

\begin{tabular}{|c|c|c|c|c|c|c|c|c|c|}
\hline & & & 1970 & 2016 & & & 1993 & 2016 & \\
\hline & $N_{S}$ & $M K T$ & $H M L$ & $S M B$ & $U M D$ & $M K T$ & $H M L$ & $S M B$ & $U M D$ \\
\hline$\overline{\overline{\lambda^{\Delta}}}$ & 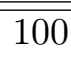 & 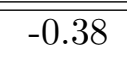 & 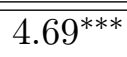 & "-0.50 & 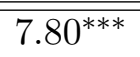 & $\overline{-0.36}$ & 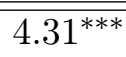 & -0.33 & 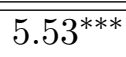 \\
\hline$t$-stat & & $(-1.20)$ & $(5.61)$ & $(-0.65)$ & $(5.46)$ & $(-0.91)$ & $(4.93)$ & $(-0.34)$ & $(3.35)$ \\
\hline$\lambda^{\Delta}$ & 269 & -0.15 & $2.98^{* * *}$ & -0.71 & $7.65^{* * *}$ & 0.20 & $2.73^{* * *}$ & -1.00 & $6.09^{* * *}$ \\
\hline$t$-stat & & $(-0.62)$ & (4.09) & $(-1.09)$ & (5.57) & $(0.84)$ & $(4.01)$ & $(-1.29)$ & $(3.60)$ \\
\hline$\overline{\lambda^{S}}$ & 100 & $6.56^{* * *}$ & $7.49^{* * *}$ & 0.92 & $9.28^{* * *}$ & $7.45^{* *}$ & $6.21^{* *}$ & 1.91 & 5.96 \\
\hline$t$-stat & & $(2.73)$ & $(3.99)$ & $(0.54)$ & $(3.93)$ & $(2.29)$ & $(2.19)$ & $(0.78)$ & (1.58) \\
\hline$\lambda^{S}$ & 269 & $6.78^{* * *}$ & $5.78^{* * *}$ & 0.71 & $9.13^{* * *}$ & $8.01^{* *}$ & 4.63 & 1.24 & $6.52^{*}$ \\
\hline$t$-stat & & $(2.83)$ & $(3.11)$ & $(0.42)$ & $(3.90)$ & $(2.48)$ & $(1.60)$ & $(0.51)$ & $(1.76)$ \\
\hline$\overline{\lambda^{M F}}$ & - & $6.93^{* * *}$ & 2.80 & 1.42 & 1.47 & $7.82^{* *}$ & 1.91 & 2.24 & 0.43 \\
\hline$t$-stat & & $(2.86)$ & (1.63) & $(0.79)$ & $(0.60)$ & $(2.41)$ & $(0.69)$ & $(0.93)$ & $(0.11)$ \\
\hline $\bar{T}$ & & 564 & 564 & 564 & 564 & 282 & 282 & 282 & 282 \\
\hline $\bar{N}_{M F}$ & & 1894 & 1894 & 1894 & 1894 & 3290 & 3290 & 3290 & 3290 \\
\hline
\end{tabular}


innovation series using their matrix-completed values $\phi_{V X O}^{\prime} g_{M L}$ and $\phi_{T E D}^{\prime} g_{F L}$ from the PCA-ALS procedure previously described.

Lasso simultaneously prevents overfitting in the time-series regressions by shrinking coefficients and selects covariates by zeroing out coefficients that would otherwise be close to zero. Both features facilitate the use of many liquidity proxies even when a mutual fund is relatively shortlived. Moreover, we no longer need to choose which measure(s) best approximate the costs faced by each fund, and indeed, different liquidity measures may be more salient for different mutual funds. First-stage penalization also knocks out spurious strategy loadings for funds that take on risk exposures unintentionally — a small non-zero loading taken en route to implementing a different strategy will be zeroed out. ${ }^{16}$

The obvious concern when using Lasso is the selection of the penalization parameter $\kappa$. Following standard practice (e.g., Bühlmann and van de Geer (2011), Hastie, Tibshirani, and Wainwright (2015)), we use $k$-fold cross-validation to select $\kappa$. Cross-validation works as follows. First, select a candidate value of $\kappa_{m}$ and partition the sample into $k$ equal "folds"; in our case, we choose the MATLAB default of $k=10$. Next, for each fold, estimate the model on the set difference of the full sample and the partition. Then calculate the mean-squared error of the estimated model on the fold that was set aside. This procedure provides $k$ pseudo-out-of-sample (POOS) $R^{2} \mathrm{~s}$ as a function of $\kappa_{m}$. Finally, repeat this procedure for a range of $\kappa_{m}$, and select $\kappa$ as the value $\kappa_{m}$ that maximizes the average POOS $R^{2}$. Intuitively this process tames overfitting by selecting the model with the best out-of-sample predictive properties. ${ }^{17}$

Table IV presents results using the Lasso first stage described by Equation (8). Most importantly, the coefficients on $\lambda^{\Delta}$ are of similar size and statistical significance as they are in the preceding two tables. Using the Lasso results in one key change from the prior table, however: the point estimate for $U M D$ compensation for mutual funds becomes negligible in the full sample and negative in the recent sample. This feature is consistent with mutual funds earning compensation for momentum exposure only to the extent that momentum also embeds liquidity risk. By including a rich set of liquidity and liquidity risk proxies rather than two principal components, we allow this source of compensation to be spanned in the first stage, thereby effectively kicking out $U M D$ as a priced factor on the set of mutual fund test assets. Because $\lambda_{U M D}^{M F}$ is an upper bound on mutual fund compensation for $U M D$ exposure, Table (IV) implies that momentum strategies are not implementable for the typical mutual fund.

\footnotetext{
${ }^{16}$ We also run a version of Equation (8) in which we do not penalize return factor loadings. Doing so avoids selecting among return factors or shrink their coefficients. Results are highly similar to the baseline results of Table II.

${ }^{17}$ Remarkably, Chetverikov, Liao, and Chernozhukov (2017) demonstrate that time-series betas estimated using the Lasso converge to the true betas at rate $\sqrt{n}$, up to a negligible log term. Because the convergence rate is comparable to that of OLS, using Lasso in the first stage does not exacerbate the errors-in-variables problem endemic to FamaMacBeth regression. We therefore follow standard practice in taking betas as "known" inputs into the Fama-MacBeth cross-sectional regressions and adjust standard errors for heteroskedasticity and serial correlation.
} 
Table IV: Implementation Cost Estimates in Fama-MacBeth Regressions — Liquidity Lasso

Table reports Fama-MacBeth estimates of the compensation for factor exposure for stock portfolios (second panel), domestic equity mutual funds (third panel), and their difference (top panel). Coefficients are the average cross-sectional slopes $\bar{\lambda}_{k}$ across monthly regressions of excess returns $r_{i t}$ on time-series betas $\hat{\beta}_{i k}$,

$$
r_{i t}=\sum_{k} \lambda_{k t}^{S} \hat{\beta}_{i k} 1_{i \in S}+\sum_{k} \lambda_{k t}^{M F} \hat{\beta}_{i k} 1_{i \in M F}+\epsilon_{i t}, t=1, \ldots, T
$$

where $k$ indexes the four Carhart (1997) factors and $\lambda^{\Delta}$ is defined as $\lambda^{S}-\lambda^{M F}$. First-stage regression estimates include these factors and all market and funding liquidity proxies in a Lasso regression with portfolio-specific penalty parameters $\kappa_{i}$ chosen by 10 -fold cross validation. Liquidity proxies and stock portfolio sets are described in Section III. All coefficients are annualized and reported in percent. Standard errors are Newey-West with three lags. $t$ statistics are reported in parentheses.

(a) Equal-Weighted Stock Portfolios

\begin{tabular}{|c|c|c|c|c|c|c|c|c|c|}
\hline & \multirow[b]{2}{*}{$N_{S}$} & \multicolumn{4}{|c|}{$1970-2016$} & \multicolumn{4}{|c|}{$1993-2016$} \\
\hline & & $M K T$ & $H M L$ & $S M B$ & $U M D$ & $M K T$ & $H M L$ & $S M B$ & $U M D$ \\
\hline$\overline{\overline{\lambda^{\Delta}}}$ & 100 & -0.10 & $5.20^{* * *}$ & $1.88^{*}$ & $9.20^{* * *}$ & 0.33 & $3.44^{* * *}$ & $\begin{array}{l}1.79 \\
\end{array}$ & $6.62^{* * *}$ \\
\hline$t$-stat & & $(-0.19)$ & $(5.48)$ & $(1.83)$ & $(5.48)$ & $(0.46)$ & $(2.74)$ & $(1.28)$ & $(3.01)$ \\
\hline$\lambda^{\Delta}$ & 269 & 0.26 & $4.61^{* * *}$ & $2.30^{* *}$ & $10.25^{* * *}$ & 1.02 & $2.13^{*}$ & 2.07 & $8.03^{* * *}$ \\
\hline$t$-stat & & $(0.51)$ & $(4.37)$ & $(2.07)$ & $(6.09)$ & $(1.50)$ & $(1.72)$ & $(1.43)$ & $(3.61)$ \\
\hline$\overline{\lambda^{S}}$ & 100 & $6.92^{* * *}$ & $7.83^{* * *}$ & 3.05 & $9.63^{* * *}$ & $8.25^{* *}$ & $5.10^{*}$ & 4.25 & 5.86 \\
\hline$t$-stat & & $(2.86)$ & $(4.07)$ & $(1.56)$ & $(3.95)$ & $(2.48)$ & $(1.73)$ & $(1.51)$ & $(1.49)$ \\
\hline$\lambda^{S}$ & 269 & $7.28^{* * *}$ & $7.24^{* * *}$ & $3.47^{*}$ & $10.68^{* * *}$ & $8.93^{* * *}$ & 3.79 & 4.53 & $7.27^{*}$ \\
\hline$t$-stat & & $(3.04)$ & $(3.39)$ & (1.68) & $(4.29)$ & $(2.73)$ & (1.18) & $(1.58)$ & $(1.81)$ \\
\hline$\overline{\lambda^{M F}}$ & - & $7.02^{* * *}$ & 2.63 & 1.17 & 0.43 & $7.91^{* *}$ & 1.66 & 2.47 & -0.76 \\
\hline$t$-stat & & $(2.85)$ & (1.31) & $(0.64)$ & $(0.16)$ & $(2.40)$ & $(0.54)$ & $(0.99)$ & $(-0.18)$ \\
\hline $\bar{T}$ & & 564 & 564 & 564 & 564 & 282 & 282 & 282 & 282 \\
\hline $\bar{N}_{M F}$ & & 1894 & 1894 & 1894 & 1894 & 3290 & 3290 & 3290 & 3290 \\
\hline
\end{tabular}

(b) Value-Weighted Stock Portfolios

\begin{tabular}{|c|c|c|c|c|c|c|c|c|c|}
\hline & & & 1970 & 2016 & & & 1993 & 2016 & \\
\hline & $N_{S}$ & $M K T$ & $H M L$ & $S M B$ & $U M D$ & $M K T$ & $H M L$ & $S M B$ & $U M D$ \\
\hline$\overline{\overline{\lambda^{\Delta}}}$ & 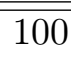 & 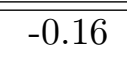 & 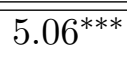 & "-0.53 & $8.81^{* * *}$ & $\begin{array}{l}-0.24 \\
\end{array}$ & 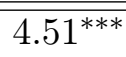 & -0.54 & "6.49*** \\
\hline$t$-stat & & $(-0.49)$ & $(5.76)$ & $(-0.71)$ & $(5.58)$ & $(-0.57)$ & $(4.73)$ & $(-0.55)$ & $(3.12)$ \\
\hline$\lambda^{\Delta}$ & 269 & -0.05 & $3.41^{* * *}$ & -0.63 & $8.51^{* * *}$ & 0.28 & $3.11^{* * *}$ & -1.22 & $7.07^{* * *}$ \\
\hline$t$-stat & & $(-0.17)$ & $(4.20)$ & $(-0.99)$ & $(5.68)$ & $(1.12)$ & $(4.25)$ & $(-1.49)$ & $(3.52)$ \\
\hline$\overline{\lambda^{S}}$ & 100 & $6.86^{* * *}$ & $7.69^{* * *}$ & 0.64 & $9.24^{* * *}$ & $7.67^{* *}$ & $6.17^{* *}$ & 1.92 & 5.73 \\
\hline$t$-stat & & $(2.84)$ & $(3.96)$ & $(0.37)$ & $(3.87)$ & $(2.33)$ & $(2.01)$ & $(0.75)$ & (1.47) \\
\hline$\lambda^{S}$ & 269 & $6.97^{* * *}$ & $6.05^{* * *}$ & 0.54 & $8.95^{* * *}$ & $8.19^{* *}$ & 4.77 & 1.24 & $6.31^{*}$ \\
\hline$t$-stat & & $(2.89)$ & $(3.12)$ & $(0.32)$ & $(3.78)$ & $(2.50)$ & $(1.50)$ & $(0.50)$ & $(1.65)$ \\
\hline$\overline{\lambda^{M F}}$ & - & $7.02^{* * *}$ & 2.63 & 1.17 & 0.43 & $7.91^{* *}$ & 1.66 & 2.47 & -0.76 \\
\hline$t$-stat & & $(2.85)$ & $(1.31)$ & $(0.64)$ & $(0.16)$ & $(2.40)$ & $(0.54)$ & $(0.99)$ & $(-0.18)$ \\
\hline $\bar{T}$ & & 564 & 564 & 564 & 564 & 282 & 282 & 282 & 282 \\
\hline $\bar{N}_{M F}$ & & 1894 & 1894 & 1894 & 1894 & 3290 & 3290 & 3290 & 3290 \\
\hline
\end{tabular}




\section{Matched Pairs Estimates of Implementation Costs}

The cross-sectional approach of the previous section compares the return compensation for an incremental unit of risk exposure taken in on-paper portfolios versus in mutual funds. Such an approach does not address the question of whether large investments by mutual funds achieve more favorable risk-reward trade-offs than marginal factor investments. For example, mutual funds may excel at taking on moderate risk exposures to a factor, but their performance may deteriorate for extreme exposures for which taking on additional leverage is needed (Frazzini and Pedersen (2014)). To answer this question, we consider the building blocks for many tradeable return factors in academia - long-short portfolios implied by characteristic sorts - and conduct a matched pairs analysis of characteristic-sorted stocks and matched mutual funds.

\section{A. Matched Pairs Methodology}

We begin by constructing characteristics for each stock and sorting stocks into quintile portfolios. Our characteristics are 60-month rolling market beta (requiring at least 24 observations), book-tomarket ratio, ${ }^{18}$ market capitalization (with scale reversed to place small stocks in the top quintile), and prior return over the previous year, skipping the latest month (the "2-12" return). We follow the methodology of Ken French's website in constructing these characteristics, and we use the provided breakpoints based on NYSE quintiles where available. In the case of rolling market betas we construct our own quintile breakpoints. For the first three characteristics, we assign portfolios at the end of June and retain assignments for July through the end of the following June. Momentum is a higher-frequency anomaly, and we sort on prior returns and retain assignments for the next month only. We then estimate two sets of betas on monthly return data for all common stocks in the CRSP universe and all U.S. domestic equity mutual funds: univariate betas with respect to a single factor $f_{k}$ and multivariate betas with respect to all four Carhart factors.

For each stock in quintile $q$ for factor $k$ in month $t$, we find the three closest mutual funds active in that month. We assess proximity using the Mahalanobis distance on betas with covariances estimated using the full sample, ${ }^{19}$ where $\beta_{k}$ determines distance in our univariate analysis, all four $\beta$ s determine distance in our multivariate analysis. Implicitly we select stocks as our matched pairs "treatment group" because we want to mimic on-paper factor portfolios as best as possible using mutual funds. Each stock is matched to three mutual funds rather than one to improve precision of the average return for mutual funds with the same risk characteristics. To ensure high match quality, we impose a maximum distance or caliper of 0.25 standard deviations for univariate matches (following Rosenbaum and Rubin (1984)'s rule-of-thumb in the context of propensity score

\footnotetext{
${ }^{18}$ We source our book-to-market ratios from the WRDS Financial Ratios Suite. We make small modifications to the provided code to extend the ratios to all stocks through the end of 2016.

${ }^{19}$ The Mahalanobis distance is $\sqrt{(x-y)^{\prime} \Sigma^{-1}(x-y)}$ for two vectors $x$ and $y$ and covariance matrix $\Sigma$. When $\Sigma$ is diagonal, it normalizes each dimension to have a unit standard deviation, and we adopt this terminology in the main text. It reduces to the Euclidean distance when $\Sigma=\mathbf{I}$.
} 
matching) and $0.25 \times 4=1$ standard deviation for four-factor matching. Stocks with fewer than three matched mutual funds within these radii are dropped.

We follow Abadie and Imbens $(2006,2011)$ to establish a bias-adjusted matched pairs estimator for each month's implementation gap by calculating the average difference between next-month returns for stocks and mutual funds. Armed with monthly implementation gap estimates, we take the average value as our full-sample estimate. We also consider differences in value-weighted returns within each month using the lagged market capitalization of the matched stocks. Appendix $\mathrm{C}$ provides a detailed description of the matched pairs methodology and evaluation of match quality.

Our analysis includes univariate and multivariate matches because each mimics a different standard asset pricing approach and because each method entails making a particular set of tradeoffs. Intuitively, matching on univariate betas answers the question of whether mutual funds are comparably good as stocks at isolating a particular characteristic; for example, do mutual funds with high (low) "value" betas achieve the same excess returns as high (low) value beta stocks? This analysis parallels a comparison between Q5-Q1 returns from two standard portfolio sorts, where one set of test assets (mutual funds) is transformed to have as similar risk attributes as possible to the other set of test assets (stocks). In favor of univariate matching is its high match rate and accurate matches along the dimension of interest, and this approach dominates when one matching feature is more important than others in determining stock and mutual fund returns. Matching on all betas answers the same question when excess returns are assessed with respect to a richer, nonparametric model that controls for possible variation in other risk factors. This multivariate-beta matching approach parallels multifactor tests such as Fama-MacBeth cross-sectional regressions in which we assess the returns to a single factor holding all other factors fixed. In favor of multivariate matching is its ability to simultaneously control for several determinants of returns to conduct a true "all else equal" analysis for stocks and mutual funds. This approach - which we favor in our application - trades off match quality in the dimension of interest with an elimination of systematic biases in the other dimensions. We discuss trade-offs of each approach in more detail in Appendix C.B.

For each matched pairs analysis, we compare the performance of stocks in high-characteristic portfolios and matched mutual funds. These differences in high-characteristic quintile returns represent a lower bound on the underperformance of mutual fund implementations of factor investing. To see why, consider the difference in factor returns for stocks and mutual funds,

$r_{S}-r_{M F}=\left(r_{S}^{\text {long }}-r_{S}^{\text {short }}\right)-\left(r_{M F}^{\text {long }}-r_{M F}^{\text {short }}\right) \geq\left(r_{S}^{\text {long }}-r_{S}^{\text {short }}\right)-\left(r_{M F}^{\text {long }}-r_{S}^{\text {short }}\right)=r_{S}^{\text {long }}-r_{M F}^{\text {long }}$.

The inequality in Equation (9) holds if mutual funds are weakly less able to implement the short side of strategies than paper shorting returns would indicate. We expect underperformance on selling the low-beta quintiles because shorting entails relatively high transaction costs. Short-side underperformance is especially plausible if we find that mutual funds also underperform on the 
long side. In addition, some firms implement positive-cost versions of anomalies such as long-only momentum, in which only the extreme "buy" portfolio is traded.

Note that we do not directly compare the performance of long-short strategies for stocks and mutual funds. We cannot short mutual funds, and underperformance on both ends of a long-short strategy, for example, because of transactions costs, would be incorrectly obscured by differencing, as such costs are additive. Instead, we settle for comparing performance on the long portfolios to establish a lower bound on the implementation costs of asset pricing factors.

\section{B. Results}

Table V reports the results of our matched pairs analysis. The $\Delta^{L M S}$ value in the upper-left corner indicates that mutual funds underperform stocks with the same market beta exposure by $2.60 \%$ per year when stocks are in the $60-80$ th percentile of the distribution of rolling market betas. We designate "LMS" as long high-market beta stocks and short low-market beta stocks to distinguish long-short market beta portfolios from the equity premium $R_{m}-R_{f}$. This implementation gap is larger than the on-paper return to an equal-weighted long-short strategy based on market beta quintiles, and roughly $40 \%$ of the annual equity premium over this period $(6.35 \%$ per year, not tabulated). Moving to the next column on the right, mutual funds continue to underperform stocks by a much-smaller $0.83 \%$ per year, and this value is no longer statistically significant. Moving down the upper-left panel we see that the implementation gap is positive and statistically significant for all factors considered. Costs are particularly high for momentum strategies, as prior literature suggests, and they are similarly high for value strategies.

The smaller point estimates in quintile four relative to quintile five is a common feature throughout the panels, and it reflects the balance of two competing forces. On one side, if per-unit costs are fixed across firms (as in Section IV.A), higher betas translate into higher total implementation gaps $\beta(h-f)$. On the other side, mutual funds select into the highest $\beta$ group, so high- $\beta$ group membership likely reflects lower per-unit underperformance $h-f$. For these reasons the product of $\beta(h-f)$ could increase or decrease as we move to more extreme $\beta$ quintiles, and empirically, the scale effect tends to dominate the selection effect.

The upper-left panel reflects performance differences between stocks and mutual funds matched on betas from a one-factor model of returns. This matching is akin to a portfolio sort in which a single characteristic is used. Other return-relevant variables are not held fixed as we vary one characteristic, so it may be that stocks and matched mutual funds vary substantially on other dimensions. For example, mutual funds trading continuation strategies like momentum are slightly less likely to trade contrarian strategies like value $\left(\rho_{\beta_{H M L}, \beta_{U M D}}=-3.8 \%\right)$, whereas momentum and value betas are positively correlated among stocks $\left(\rho_{\beta_{H M L}, \beta_{U M D}}=+14.3 \%\right)$. The bottom-left panel addresses this concern by reporting return differences in high-characteristic portfolios between stocks and mutual funds matched on the four Carhart (1997) factors. In this analysis we estimate 


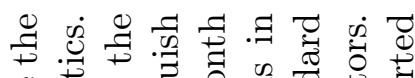
仓 艺 过

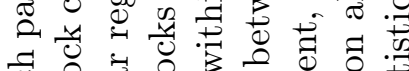
牙 वृ 俒

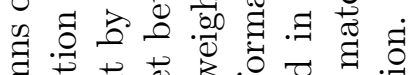

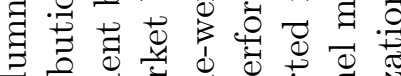

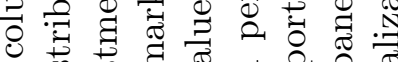
no

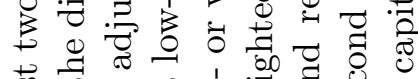

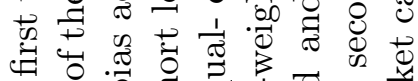
然

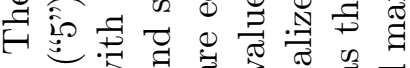
xं 0 क क क

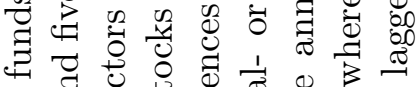

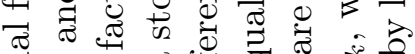
政

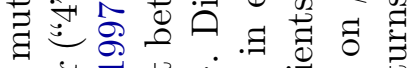

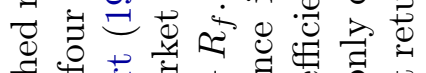

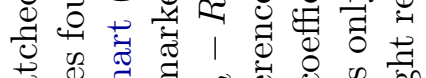

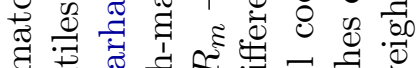

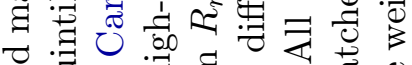

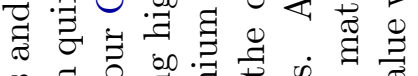

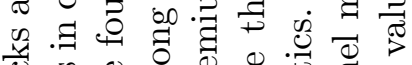

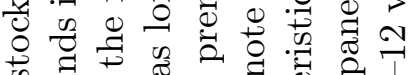

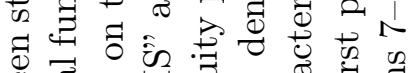

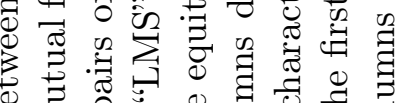

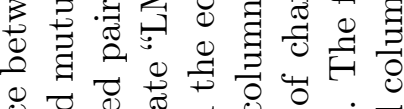

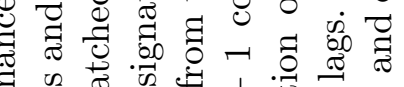

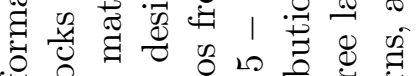

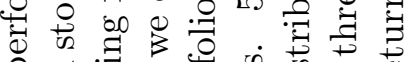

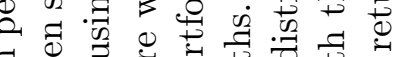

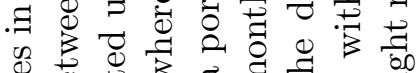
过

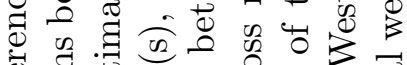
进

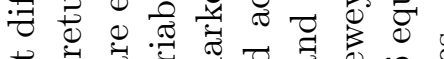

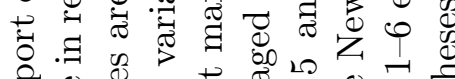

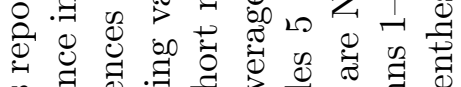

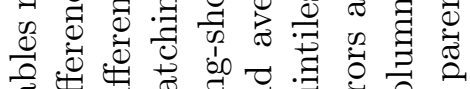

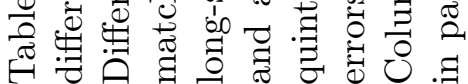
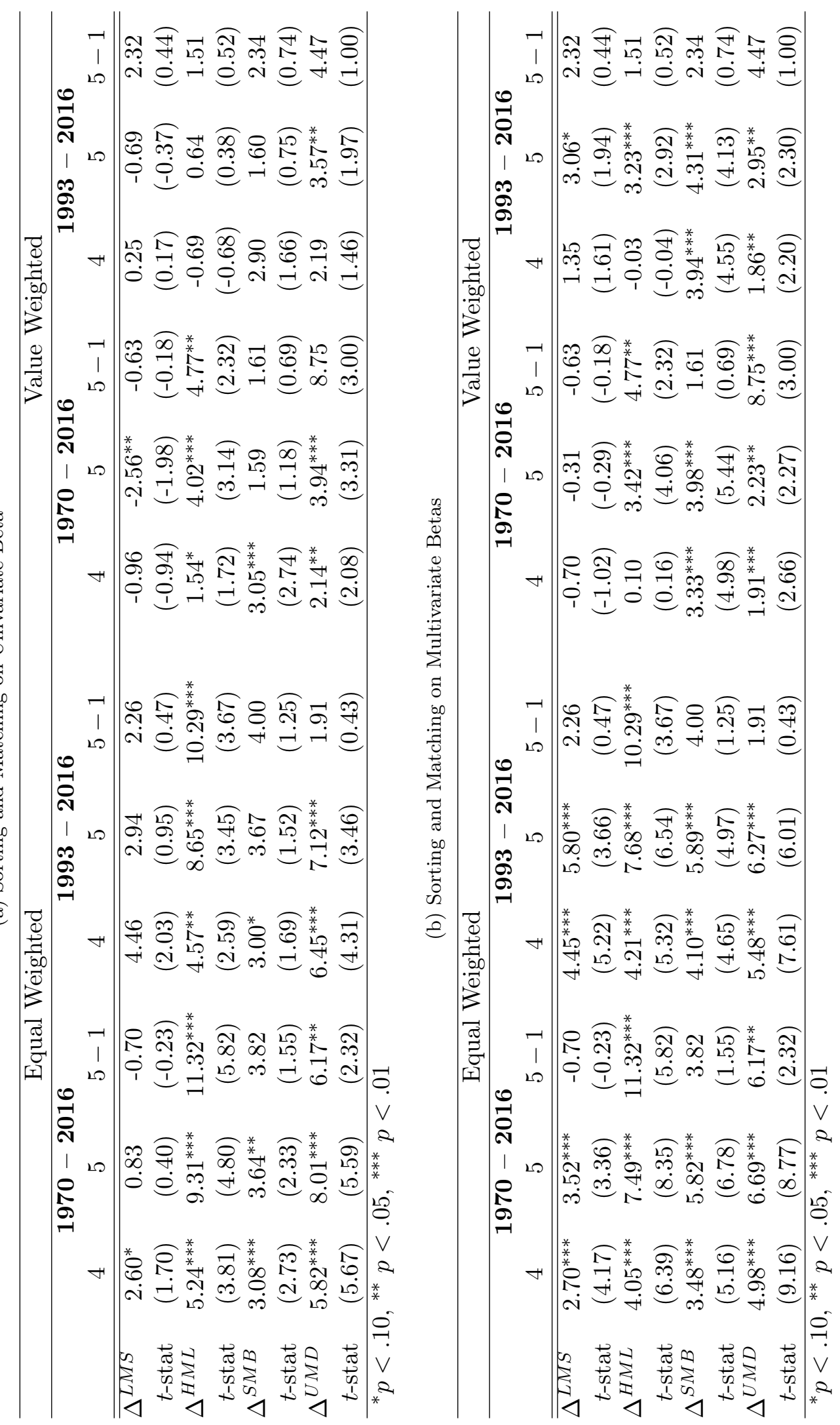
multifactor betas using four-factor time-series regressions as in Equation (1).

Controlling for the three non-sorting variables has a large effect on the statistical reliability of the market and size factor implementation costs, which suggests that funds with high-beta strategies likely differ from high-beta stocks on other dimensions. In the equal-weighted specification we see that the implementation gap is large and statistically significant for quintiles four and five for all anomalies. The implementation gaps are so large, in fact, that they swamp or severely attenuate factor returns for all four factors considered, regardless of whether we include all stocks or focus only on the investable set of matched stocks. In short, at least from an equal-weighted perspective, no factors earn returns after real-world costs during the 1970-2016 period. This finding also holds in the right panel for the 1993-2016 period, in which the four academic factors are known and the mutual fund universe is far more developed (see Figure I).

Columns 7-12 of the top panel present value-weighted results. The contrast between equal- and value-weighted results testifies to the importance of size in dictating the ability of mutual funds to mimic return factors; differences in performance attenuate dramatically when small, harder-toaccess stocks are downweighted. Focusing first on the univariate matches, mutual fund underperformance on value, size, and momentum strategies falls by roughly half relative to the corresponding equal-weighted results, and underperformance on the long-short market beta strategy reverts to zero or even to a negative value. As we find in Section IV, mutual funds capture returns to market beta quite well.

Turning to the multivariate matches in the value-weighted specification restores our finding that mutual funds underperform matched stocks for the non-market factors. Implementation gaps are again smaller than in the equal-weighted results, but the magnitudes are nonetheless economically large for the three main anomalies: $0.1 \%-3.42 \%$ for value against a time-series average return of $4.77 \%$ for value-weighted HML; $3.33 \%-3.98 \%$ for size against a time-series average return of $1.61 \%$ for SMB; and $1.91 \%-2.23 \%$ against a time-series average return of $8.75 \%$ for UMD. These differences carry over to the more recent 1993-2016 interval, as well. In sum, we replicate the high implementation costs of these factors, and such performance attrition is a stark departure from the muted effects of trading costs often considered in the academic literature.

Taken together, these matched-pair results agree qualitatively with the cross-sectional results for three of the four factors ( $M K T / L M S, H M L$, and $U M D)$, but they disagree for size. This disagreement is likely attributable to the fact that $S M B$ beta is not associated with cross-sectional differences in average returns - and the cross-sectional approach thus reveals no difference in compensation to $S M B$ exposure - whereas the small-size characteristic is associated with higher average returns. Consequently we observe high returns on small-stock portfolios in the matched pairs approach, and mutual funds clearly cannot capture these returns well in practice. 


\section{Cost Estimates Over Time and Across Funds}

\section{A. Comparison with Previous Implementation Cost Estimates}

Our analysis thus far considers the implementation costs of factor strategies for representative mutual funds, with no attention paid to the size of the fund. Variation in investors' trading technologies may drive a wedge between a typical asset manager and the marginal investor in an anomaly, and by dividing asset managers into groups we can learn whether factors are broadly (in)accessible or whether they generate positive net-of-costs returns for a subset of managers. Our results below suggest that the longstanding disagreement on the profitability of momentum strategies follows because market-wide and single-firm analyses, e.g., Lesmond, Schill, and Zhou (2004) and Frazzini, Israel, and Moskowitz (2015) respectively, focus on different sides of this wedge.

In this section, we briefly demonstrate the utility of our cross-sectional approach for examining segments of asset managers. Motivated by extensive work relating fund size to gross-of-fees performance (e.g., Berk and Green (2004), Pastor, Stambaugh, and Taylor (2015), and Berk and van Binsbergen (2015)), we split fund groups into groups based on lagged total net assets (TNA). We then run our second-stage cross-sectional regressions (2) separately for each asset manager TNA group. ${ }^{20}$ In principle we could complement this analysis with a matched pairs approach, but dividing the set of possible mutual funds into several groups significantly reduces match quality in the tail portfolios. The cross-sectional regression approach does not have this problem because it uses all information to estimate implementation gaps rather than "local" information only.

Table VI presents results from these segmented regressions. As in Tables II-IV, mutual funds generally achieve returns to market factor exposure comparable to those of on-paper stock portfolios. HML also earns positive compensation, and returns to $H M L$ are collectively different from zero in two of three specifications. Other point estimates are more variable across mutual fund size categories. Focusing on momentum, the smallest mutual funds have the highest returns to momentum factor exposure, and momentum compensation is monotonically decreasing with mutual fund size (with one exception in the baseline specification). The differences in compensation across mutual fund size categories are also economically significant in all specifications despite individual momentum coefficients typically not being different from zero. We can also reject non-monotonicity of momentum compensation across size categories using the bootstrap test of Patton and Timmermann (2010) - momentum strategy performance is decreasing in fund size. This feature makes intuitive sense in that momentum is a high-turnover strategy, and larger funds suffer greater market impact costs in implementing momentum than smaller funds. In the Lasso specification, $\lambda \mathrm{s}$

\footnotetext{
${ }^{20}$ Groups are assigned separately for each date with cutoffs based on December 2016 USD. The micro-fund group has $T N A_{t}<\$ 10 M$ and comprises $5.2 \%$ of the data. This group is selected in that it consists of past losers whose assets had at one time exceeded $\$ 10 M$. The small-fund group has $\$ 10 M<T N A_{t}<\$ 50 M$ and comprises $22.8 \%$ of the data. The medium-fund group has $\$ 50 M<T N A_{t}<\$ 250 M$ and comprises $31.8 \%$ of the data. The large-fund group has $\$ 250 M<T N A_{t}<\$ 1 B$. and comprises $22.5 \%$ of the data. The mega-fund group has $T N A_{t}>\$ 1 B$ and comprises $17.7 \%$ of the data.
} 

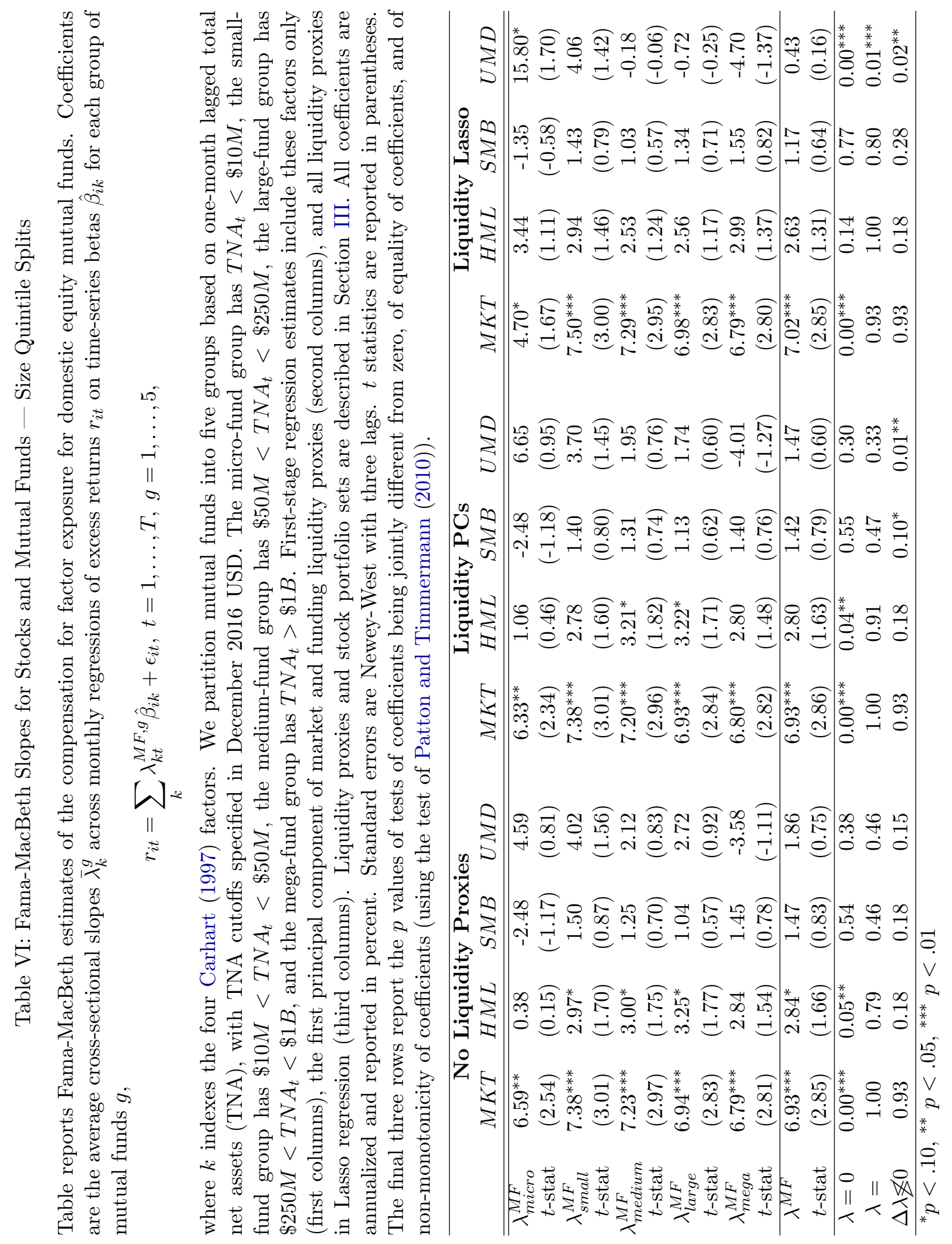
are also statistically different from one another at the $1 \%$ level. We conclude that variation across mutual funds is important when considering the net-of-costs returns to the momentum factor.

Table VII compares these real-world factor return estimates with estimates from selected influential works in the literature. Novy-Marx and Velikov (2016) estimate trading costs by summing effective bid-ask spreads of traded securities, and by their reckoning, momentum's trading costs reduce the gross strategy return from $16.0 \%$ per year to $8.16 \%$ per year (Table 3 of their paper). These positive momentum returns net-of-costs likely significantly overstate achievable returns, however, because their calculation ignores the price impact of trading that is particularly relevant to institutional investors and is considered by others in the literature.

Papers that consider a wider range of trading costs reach mixed conclusions on the implementability of momentum. Korajczyk and Sadka (2004) suggest that momentum profits exist only at small scales (the table reflects only proportional costs, and by their reckoning, non-proportional costs quickly overwhelm strategy returns), and Lesmond, Schill, and Zhou (2004) argue that high transactions costs preclude profitable momentum strategies altogether. Because these studies estimate transactions costs functions using all TAQ transactions, their average implementation cost estimates are smoothed over size quintiles and over trades unrelated to momentum strategies. As a consequence these authors find a result like the $\lambda^{M F}$ of Tables II-IV, whereby momentum has an economically unimportant premium for real-world asset managers.

When we focus only on small asset managers, the picture looks quite different. Depending on the specification considered, we find that small firms earn $4.5 \%-15.8 \%$ per year per unit of momentum exposure $\left(\lambda_{T N A<\$ 10 M}\right)$. Combining these results we find that both sets of authors are correct; which momentum premium is of greater interest hinges on whether the researcher evaluates representative firms, as in benchmarking applications, or marginal investors, as in discussions of market efficiency. Intriguingly we find that the largest mutual funds earn the most negative compensation for momentum exposure, suggesting that the firm examined in Frazzini, Israel, and Moskowitz (2015) is an outlier, or that non-mutual fund asset managers have different compensation schedules for factor exposure.

\section{B. Implementation Costs Over Time}

Figure II adds a time-series dimension to the average risk price differences of Tables II-IV. ${ }^{21}$ For each panel we plot the log return of the "on-paper" investments in each factor with a unit risk loading minus the corresponding log return on mutual fund investments. To do this we invoke the interpretation of Fama-MacBeth coefficients $\lambda_{k t}$ as the date $t$ return on a portfolio with a unit

loading on factor $k$ and zero loading on all other factors. Our series is the centered rolling difference

\footnotetext{
${ }^{21}$ In the interest of brevity we suppress the corresponding plots for the matched pairs analysis.
} 
Table VII: Comparison with Selected Factor Profitability Estimates from Prior Work

Table presents estimates of factor strategy returns. The top panel reports cross-sectional slopes from Fama-MacBeth regressions as in Table VI. For brevity we report only the estimates in which liquidity proxy principal components appear in the time-series step, and we focus on the slopes for the full sample of mutual funds and for the largest mutual funds as measured by lagged total net assets. As before, standard errors are Newey-West with three lags. The second panel presents valueweighted momentum strategy returns from Table IV of Korajczyk and Sadka (2004). Alphas are constructed relative to the Fama-French three factors. $\alpha_{n e t}^{e s p r .}$ and $\alpha_{n e t}^{q s p r}$. represent excess momentum returns net of proportional costs as measured by effective spreads and quoted spreads, respectively. The third panel reports equal-weighted strategy returns from Table 3 of Lesmond, Schill, and Zhou (2004) (value-weighted returns are not reported). $r_{\text {net }}^{L D V}$ and $r_{\text {net }}^{\text {direct }}$ are momentum returns net of Lesmond, Ogden, and Trzcinka (1999)-implied costs and "direct" costs (consisting of bid-ask spreads and trading commissions), respectively. The fourth panel tabulates realized strategy returns from Table IV of Frazzini, Israel, and Moskowitz (2015). The final panel reports value-weighted strategy returns net of Hasbrouck (2009)-implied effective spreads from Table 3 of Novy-Marx and Velikov (2016). Throughout returns are annualized and $t$ statistics are reported in parentheses.

\begin{tabular}{|c|c|c|c|c|}
\hline & & $H M L$ & $S M B$ & $U M D$ \\
\hline \multirow{4}{*}{$\begin{array}{l}\text { Cross-Sectional Slopes w/ PCA } \\
\text { 1970-2016 }\end{array}$} & $\lambda^{M F}$ & 2.80 & 1.42 & 1.47 \\
\hline & $t$-stat & $(1.63)$ & $(0.79)$ & $(0.60)$ \\
\hline & $\lambda_{T N A>\$ 1 B}^{M F}$ & 2.80 & 1.40 & -4.01 \\
\hline & $t$-stat & $(1.48)$ & $(0.76)$ & $(-1.27)$ \\
\hline \multirow{6}{*}{$\begin{array}{l}\text { Korajczyk and Sadka (2004) } \\
\qquad 1967-1999\end{array}$} & $\alpha_{\text {gross }}$ & & & $6.84^{* * *}$ \\
\hline & $t$-stat & & & $(4.54)$ \\
\hline & $\alpha_{n e t}^{e s p r .}$ & & & $5.40^{* * *}$ \\
\hline & $t$-stat & & & $(3.59)$ \\
\hline & $\alpha_{n e t}^{q s p r .}$ & & & $4.80^{* * *}$ \\
\hline & $t$-stat & & & $(3.17)$ \\
\hline \multirow{6}{*}{$\begin{array}{l}\text { Lesmond, Schill, and Zhou (2004) } \\
\text { 1980-1998 }\end{array}$} & $r_{\text {gross }}$ & & & $7.83^{* * *}$ \\
\hline & $t$-stat & & & $(6.22)$ \\
\hline & $r_{n e t}^{L D V}$ & & & 0.13 \\
\hline & $t$-stat & & & $(0.07)$ \\
\hline & $r_{\text {net }}^{\text {direct }}$ & & & 2.24 \\
\hline & $t$-stat & & & $(1.22)$ \\
\hline \multirow{4}{*}{$\begin{array}{l}\text { Frazzini, Israel, and Moskowitz (2015) } \\
\qquad 1986-2013\end{array}$} & $r_{\text {gross }}$ & 4.86 & $7.98^{* * *}$ & 2.26 \\
\hline & $t$-stat & $(1.12)$ & $(3.01)$ & $(0.40)$ \\
\hline & $r_{n e t}$ & 3.51 & $6.52^{* *}$ & -0.77 \\
\hline & $t$-stat & $(0.80)$ & $(2.48)$ & $(-0.14)$ \\
\hline \multirow{4}{*}{$\begin{array}{l}\text { Novy-Marx and Velikov (2016) } \\
\text { 1963-2013 }\end{array}$} & $r_{\text {gross }}$ & $5.64^{* * *}$ & $3.96^{*}$ & $15.96^{* * *}$ \\
\hline & $t$-stat & $(2.68)$ & (1.66) & $(4.80)$ \\
\hline & $r_{n e t}$ & $5.04^{* *}$ & 3.36 & $8.16^{* *}$ \\
\hline & $t$-stat & $(2.39)$ & (1.44) & $(2.45)$ \\
\hline
\end{tabular}

${ }^{*} p<.10,{ }^{* *} p<.05,{ }^{* * *} p<.01$ 
Figure II: Rolling Performance Difference Between Mutual Funds and Stocks $(\beta=1)$

Figures plot the rolling difference between log Fama-MacBeth cross-sectional slopes for stock portfolios $(S)$ and mutual funds $(M F)$. Each series $y_{k}(t)$ equals the centered rolling difference

$$
y_{k}(t)=\sum_{s=t-6}^{t+6} \log \left(1+\lambda_{k t}^{S}\right)-\log \left(1+\lambda_{k t}^{M F}\right),
$$

where $\lambda_{k t}$ are cross-sectional slopes from monthly regressions of excess returns $r_{i t}$ on time-series betas $\hat{\beta}_{i k}$. Each figure plots differences in slopes for which the time-series regression includes no liquidity proxies, the first principal component for market liquidity proxies and funding liquidity proxies, and all liquidity proxies with Lasso penalization ( $\kappa_{i}$ chosen by 10 -fold cross validation). Stock portfolio slopes are estimated using all 269 portfolios described in Section III. Solid lines depict averages of series means. NBER recessions are in gray.

(a) $M K T$ Costs

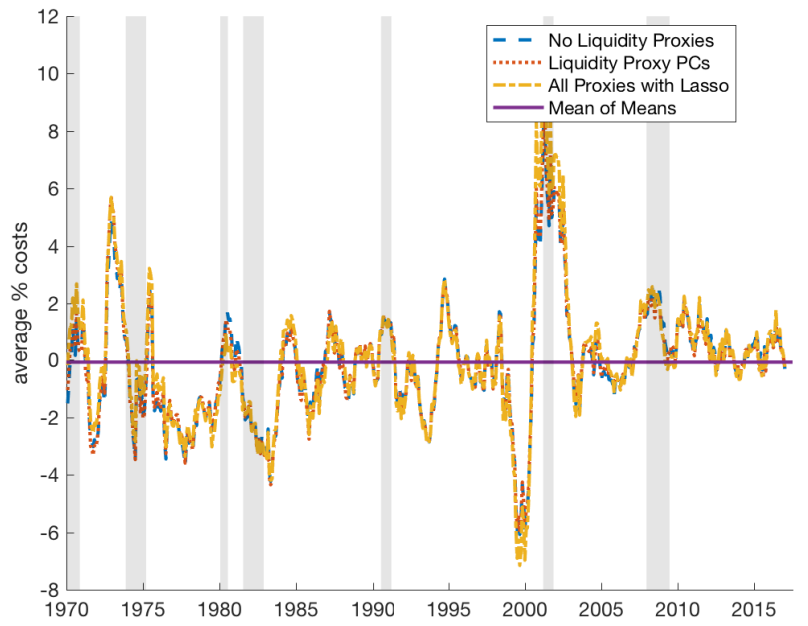

(c) $S M B$ Costs

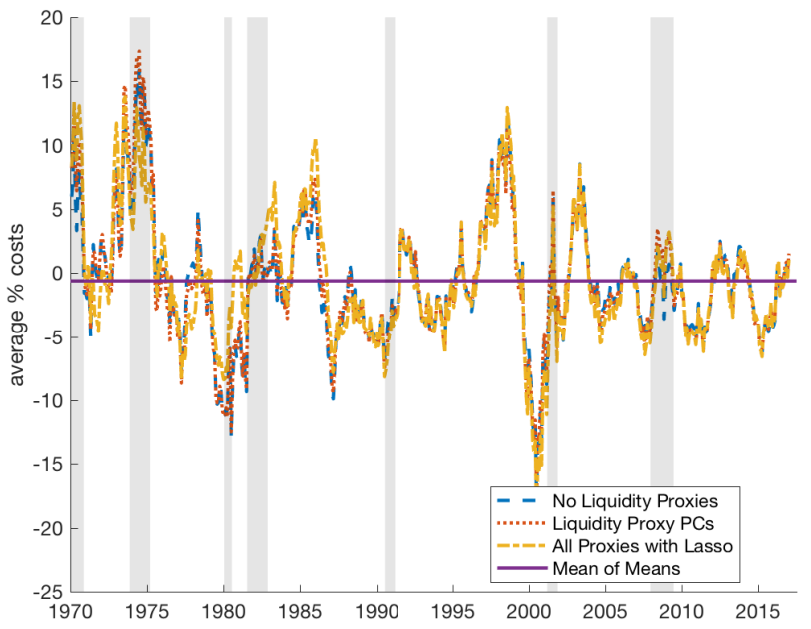

(b) $H M L$ Costs

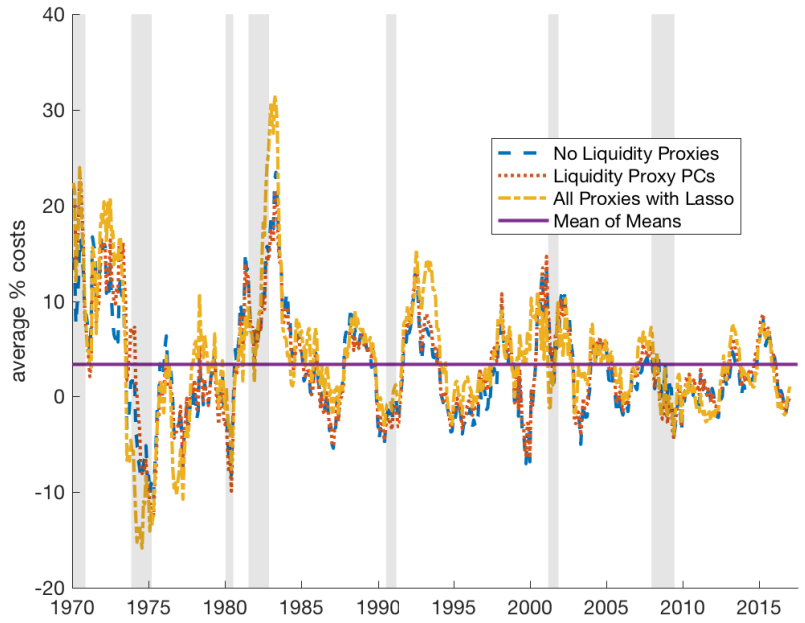

(d) $U M D$ Costs

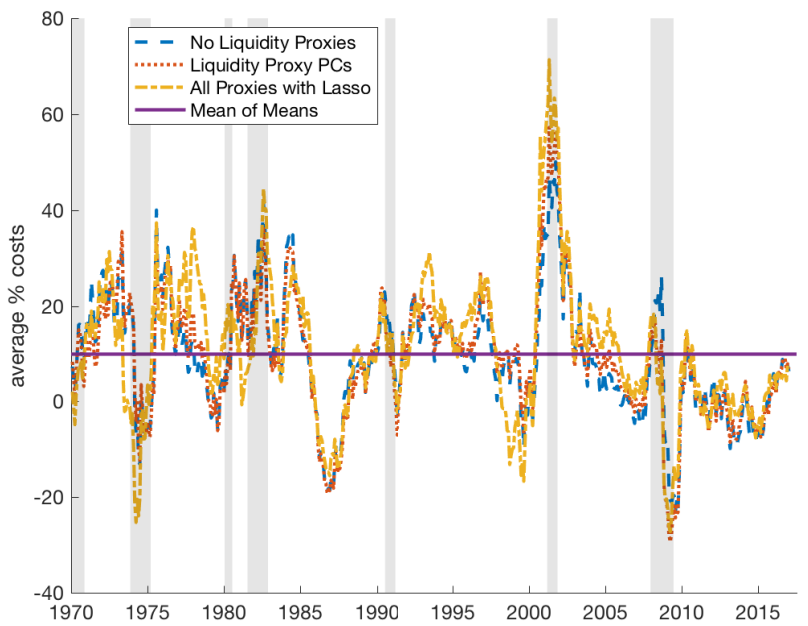


in performance,

$$
y_{k}(t)=\sum_{s=t-6}^{t+6} \log \left(1+\lambda_{k t}^{S}\right)-\log \left(1+\lambda_{k t}^{M F}\right) \approx \sum_{s=t-6}^{t+6} \lambda_{k t}^{\Delta} .
$$

This quantity has an equivalent interpretation as the relative cost associated with real-world rather than on-paper investment in factor strategies.

The four panels of Figure II depict factor implementation costs for each set of liquidity proxies using the 269 stock portfolios as the on-paper return benchmark. Although magnitudes vary slightly across specifications, the three slope series are remarkably similar for each factor. The implementation gap is clearly rank-ordered as $U M D, H M L, M K T$, and $S M B$, with large and positive implementation gaps for $U M D$ and $H M L$, no implementation gap for $M K T$, and a small negative implementation gap for $S M B$. The difference series are also affected by macroeconomic events. All four implementation gaps fall before the end of the tech bubble of the late 1990s and rise during the subsequent crash and/or the Great Recession of 2007-2009. One interpretation of this feature is that factor returns are most accessible by investment managers when market liquidity is abundant and funding constraints are unlikely to be binding.

Perhaps the most intriguing feature of Figure II is the absence of a trend in strategy implementation costs. This feature contrasts with well-documented secular declines in bid-ask spreads and commissions since 1970 (e.g., Jones (2002) and Corwin and Schultz (2012)). An equilibrium perspective on the size of the asset management sector reveals why we instead obtain a stationary time series. ${ }^{22}$ As trading technology improves and equity intermediation becomes more competitive, the cost of trading the first dollar of a factor strategy declines. Perceived sector-level alphas increase for factor investors, and aggregate inflows attract new entrants (as in Figure I) or contribute to the growth of existing fund managers (as in Berk and Green (2004)). These inflows increase the scale of factor investing, which in turn increases non-proportional transactions costs such as price impact. In equilibrium this process continues until factor alphas fall to zero for the marginal dollar. Consequently the average dollar invested in factor strategies may see no reduction in implementation costs despite improvements in trading technology.

The conjectured equilibrium adjustment mechanism hinges on non-proportional trading costsomitted by studies such as Novy-Marx and Velikov (2016) - and it rationalizes industry-level decreasing returns to scale suggested by Pastor and Stambaugh (2012) and documented by Pastor, Stambaugh, and Taylor (2015). It also generates a testable prediction that industry-level inflows increase implementation costs of factor strategies.

We analyze this relationship between implementation costs, flows, and illiquidity more formally by examining relating the cost time series with liquidity and fund flow proxies. We start by constructing illiquidity proxies as the first principal components of market liquidity proxies and of

\footnotetext{
${ }^{22}$ Augmented Dickey-Fuller tests reject the null of a unit root in implementation costs at the $0.1 \%$ significance level in all series.
} 
funding liquidity proxies, as described in Section IV.B. We also construct flow variables to capture costs associated with fund inflows and outflows. Fund flows are the component of asset growth not explained by returns,

$$
\text { flow }_{i t}=\frac{T N A_{i t}}{T N A_{i, t-1}}-\left(1+R_{i t}\right) \text {. }
$$

We summarize the distribution of flows with its first and second cross-sectional moments - the crosssectional average fund flow $(M F L O W)$ and the cross-sectional dispersion in fund flows $(D F L O W)$. In addition to reflecting returns-to-scale, flow variables are a natural candidate for explaining trading costs because large flows the mutual fund sector or reshuffling of assets among mutual funds generates liquidity demands. To improve interpretability, we normalize all right-hand-side variables to have mean zero and standard deviation one.

Table VIII reports results from a regression of $\lambda_{k t}^{\Delta}$ on the liquidity and fund flow distribution proxies,

$$
\lambda_{k t}^{\Delta}=\alpha+\beta_{M F L O W} M F L O W+\beta_{D F L O W} D F L O W+\beta_{M L} P C_{M L}+\beta_{F L} P C_{F L}+\epsilon_{k t} .
$$

We report only value-weighted results for the 269 stock portfolios because relations between costs and liquidity proxies are quite similar for value-weighted and equal-weighted stock portfolios and for 100 and 269 stock portfolios. Likewise to be succinct we report only implementation costs in the baseline specification and with liquidity proxy principal components in Fama-MacBeth time-series regression step.

We draw four lessons from Table VIII. ${ }^{23}$ First, the constant terms are large and positive for $H M L$ and $U M D$, confirming that the time-invariant component of implementation costs from Equation (4) is large and positive for these factors. Second, focusing on flows, average inflows are associated with higher implementation costs for value and momentum factors, and cross-sectional dispersion in flows is weakly associated with lower implementation costs for these factors. We find no or unreliable relations for market and size factors, as is expected because these costs are small in magnitude to begin with. We interpret these relations as suggestive evidence that (1) inflows are expensive from a transactions-cost standpoint for funds trading value and momentum strategies, thereby contributing to diseconomies of scale and stationary average implementation costs, and (2) reallocation of funds within the mutual fund sector may increase other-funds' liquidity trading (in a Kyle (1985) sense), thereby reducing transactions costs for value and momentum traders. Third, focusing on illiquidity principal components, market illiquidity typically increases implementation costs. Intuitively trading becomes more expensive when market liquidity is low. Fourth, funding illiquidity typically decreases implementation costs. We conjecture that mutual funds are insulated from funding liquidity shocks that affect more highly levered institutional asset managers like

\footnotetext{
${ }^{23}$ Low $R^{2}$ s throughout are attributable in large part to the noisiness of differences in monthly factor realizations for stocks and mutual funds.
} 


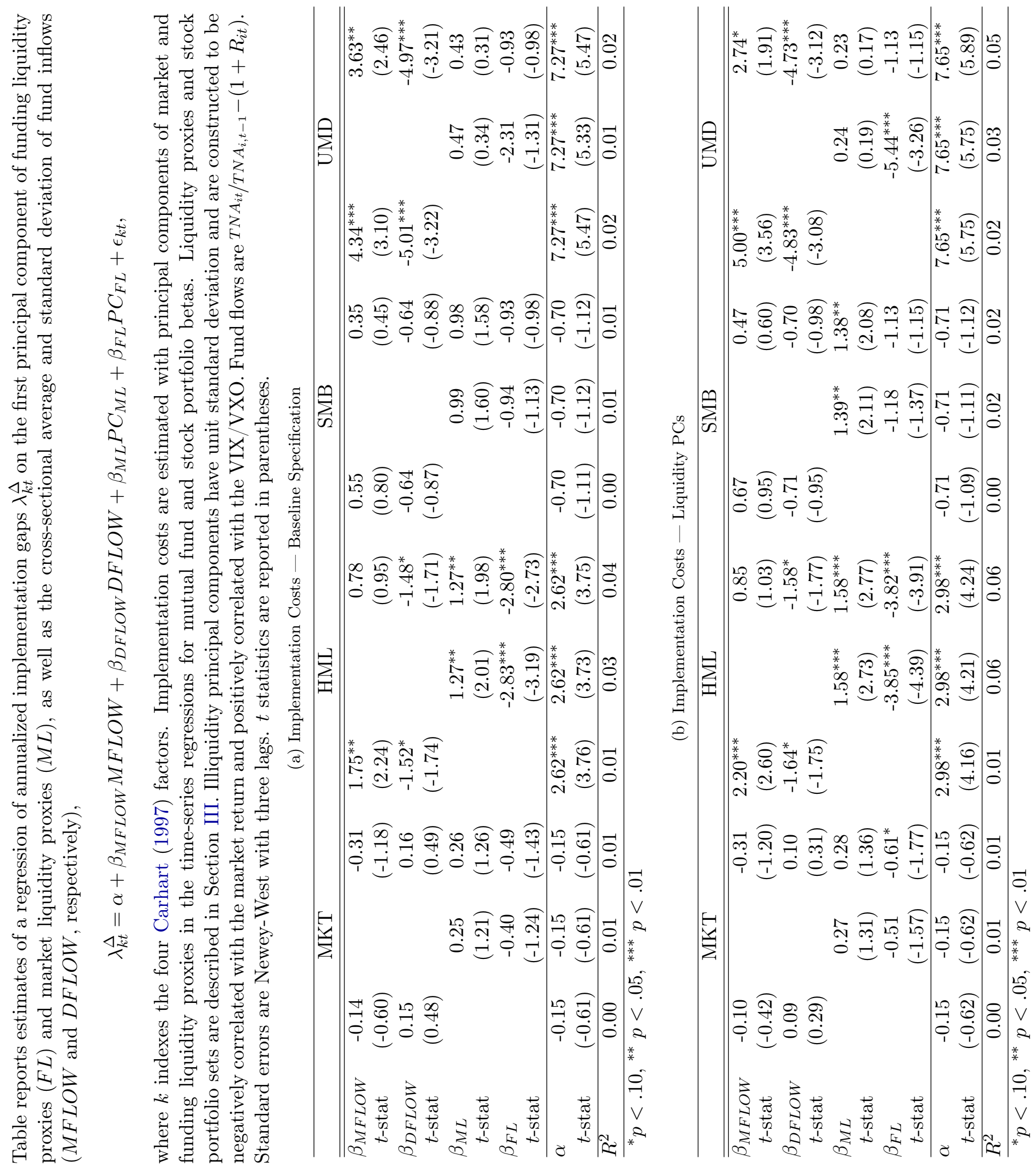


hedge funds (Sadka (2010) and Boyson, Stahel, and Stulz (2010), among others, discuss hedge funds' particular vulnerability to funding liquidity shocks), and hence mutual funds can acquire the ingredients of factor strategies from distressed asset managers at a discount during times of strained funding liquidity.

\section{Conclusion}

Existing methods for assessing the implementation costs of financial market anomalies use proprietary trading data for single firms or market-wide trading data combined with parametric transactions cost models. We propose two new methods (an extension of the Fama-MacBeth approach, and a matched pairs approach) to estimate implementation costs using only returns data from stocks and mutual funds. Doing so frees us from the requirement of specifying factor trading strategies and transaction costs models that may be incomplete or misspecified. Moreover, the ready availability of returns data for a large number of investment managers enables the examination of factor implementation costs for a large investment management universe.

Both of our proposed approaches demonstrate that mutual funds are generally poorly compensated for exposure to common risk factors. Our estimates based on Fama-MacBeth regressions imply that implementation costs erode almost the entirety of the return to value and momentum strategies for typical mutual funds, but have little effect on market and size factor strategies. Our estimates based on matched pairs suggest comparable performance attrition for value and momentum strategies, and they differ in revealing high costs to investing in small-stock characteristic portfolios.

Taken together, these results paint a sobering picture of the real-world implementability of the most important financial market anomalies. We agree with Lesmond, Schill, and Zhou (2004)'s analysis that momentum profits in particular may be out of reach for the typical asset manager. In this respect markets may be efficient from the perspective of representative mutual funds, even if outlier funds see a very different picture of risk and return net-of-costs (e.g., Frazzini, Israel, and Moskowitz (2015)'s asset manager).

Our approaches are readily extended to a wide range of candidate return factors provided that these are reflected in mutual fund exposures. Common anomalies like size, value, and momen-

tum clearly meet this requirement. In future research we will apply these tools more broadly to investigate whether other residents of the factor zoo truly can survive in the wild. 


\section{References}

Abadie, Alberto and Guido W. Imbens. 2006. "Large Sample Properties of Matching Estimators for Average Treatment Effects." Econometrica 74 (1):235-267.

— 2011. "Bias-Corrected Matching Estimators for Average Treatment Effects." Journal of Business 8 Economic Statistics 29 (1):1-11.

Amihud, Yakov. 2002. "Illiquidity and Stock Returns: Cross-Section and Time-Series Effects." Journal of Financial Markets 5 (1):31 - 56.

Arnott, Robert D., Vitali Kalesnik, and Lillian J. Wu. 2017. "The Incredible Shrinking Factor Return." Working paper.

Asness, Clifford S., Tobias J. Moskowitz, and Lasse Heje Pedersen. 2013. "Value and Momentum Everywhere." The Journal of Finance 68 (3):929-985.

Banz, Rolf W. 1981. "The Relationship Between Return and Market Value of Common Stocks." Journal of Financial Economics 9 (1):3 - 18.

Barroso, Pedro and Pedro Santa-Clara. 2015. "Momentum Has Its Moments." Journal of Financial Economics 116 (1):111 - 120.

Basu, S. 1977. "Investment Performance of Common Stocks in Relation to Their Price-Earnings Ratios: A Test of the Efficient Market Hypothesis." The Journal of Finance 32 (3):663-682.

Berk, Jonathan B. and Richard C. Green. 2004. "Mutual Fund Flows and Performance in Rational Markets." Journal of Political Economy 112 (6):1269-1295.

Berk, Jonathan B. and Jules H. van Binsbergen. 2015. "Measuring Skill in the Mutual Fund Industry." Journal of Financial Economics 118 (1):1 - 20.

Boyson, Nicole M., Christof W. Stahel, and René M. Stulz. 2010. "Hedge Fund Contagion and Liquidity Shocks." The Journal of Finance 65 (5):1789-1816.

Breen, William J., Laurie Simon Hodrick, and Robert A. Korajczyk. 2002. "Predicting Equity Liquidity." Management Science 48 (4):470-483.

Brunnermeier, Markus K. 2009. "Deciphering the Liquidity and Credit Crunch 2007-2008." The Journal of Economic Perspectives 23 (1):77-100.

Bühlmann, Peter and S. van de Geer. 2011. Statistics for High-Dimensional Data: Methods, Theory, and Applications. Springer Series in Statistics. 
Carhart, Mark M. 1997. "On Persistence in Mutual Fund Performance." The Journal of Finance $52(1): 57-82$.

Chen, Zhiwu, Werner Stanzl, and Masahiro Watanabe. 2002. "Price Impact Costs and the Limit of Arbitrage." Working paper.

Chetverikov, Denis, Zhipeng Liao, and Victor Chernozhukov. 2017. "On Cross-Validated Lasso." Working paper.

Cochrane, John H. 2011. "Presidential Address: Discount Rates." The Journal of Finance 66 (4):1047-1108.

Corwin, Shane A. and P. Schultz. 2012. "A Simple Way to Estimate Bid-Ask Spreads from Daily High and Low Prices." The Journal of Finance 67 (2):719-760.

Engle, Robert, Robert Ferstenberg, and Jeffrey Russell. 2012. "Measuring and Modeling Execution Cost and Risk." The Journal of Portfolio Management 38 (2):14-28.

Fama, Eugene F. 1970. "Efficient Capital Markets: A Review of Theory and Empirical Work." The Journal of Finance 25 (2):383-417.

Fama, Eugene F. and K. R. French. 2010. "Luck Versus Skill in the Cross-Section of Mutual Fund Returns." The Journal of Finance 65 (5):1915-1947.

Fama, Eugene F. and Kenneth R. French. 1992. "The Cross-Section of Expected Stock Returns." Journal of Finance 47 (2):427-465.

Fama, Eugene F. and James D. MacBeth. 1973. "Risk, Return, and Equilibrium: Empirical Tests." Journal of Political Economy 81 (3):607-636.

Frazzini, Andrea, Ronen Israel, and Tobias J. Moskowitz. 2015. "Trading Costs of Asset Pricing Anomalies." Working paper.

Frazzini, Andrea and Lasse Heje Pedersen. 2014. "Betting Against Beta." Journal of Financial Economics $111(1): 1-25$.

Giglio, Stefano and Dacheng Xiu. 2017. "Inference on Risk Premia in the Presence of Omitted Factors." Working paper.

Glosten, Lawrence R and Lawrence E Harris. 1988. "Estimating the Components of the Bid/Ask Spread." Journal of Financial Economics 21 (1):123 - 142.

Grundy, Bruce D. and J. Spencer Martin. 2001. "Understanding the Nature of the Risks and the Source of the Rewards to Momentum Investing." The Review of Financial Studies 14 (1):29-78. 
Harvey, Campbell R. 2017. "Presidential Address: The Scientific Outlook in Financial Economics." The Journal of Finance 72 (4):1399-1440.

Harvey, Campbell R., Yan Liu, and Heqing Zhu. 2016. “... and the Cross-Section of Expected Returns." The Review of Financial Studies 29 (1):5-68.

Hasbrouck, Joel. 2009. "Trading Costs and Returns for U.S. Equities: Estimating Effective Costs from Daily Data." The Journal of Finance 64 (3):1445-1477.

Hastie, T., R. Tibshirani, and M. Wainwright. 2015. Statistical Learning with Sparsity: The Lasso and Generalizations. CRC Press.

He, Zhiguo, Bryan Kelly, and Asaf Manela. 2017. "Intermediary Asset Pricing: New Evidence from Many Asset Classes." Journal of Financial Economics .

Hou, Kewei, Chen Xue, and Lu Zhang. 2017. "Replicating Anomalies." Working paper.

Imbens, Guido W. and Donald B. Rubin. 2015. Causal Inference for Statistics, Social, and Biomedical Sciences: An Introduction. Cambridge University Press, 1st ed. ed.

Jegadeesh, Narasimhan and Sheridan Titman. 1993. "Returns to Buying Winners and Selling Losers: Implications for Stock Market Efficiency." The Journal of Finance 48 (1):65-91.

- 2001. "Profitability of Momentum Strategies: An Evaluation of Alternative Explanations." The Journal of Finance 56 (2):699-720.

Jones, Charles M. 2002. "A Century of Stock Market Liquidity and Trading Costs." Working paper.

Keim, Donald B. and Ananth Madhavan. 1997. "Transactions Costs and Investment Style: An InterExchange Analysis of Institutional Equity Trades." Journal of Financial Economics 46 (3):265 $-292$.

Korajczyk, Robert A. and Ronnie Sadka. 2004. "Are Momentum Profits Robust to Trading Costs?" The Journal of Finance 59 (3):1039-1082.

Kyle, Albert S. 1985. "Continuous Auctions and Insider Trading." Econometrica 53 (6):1315-1335.

Lesmond, David A., Joseph P. Ogden, and Charles A. Trzcinka. 1999. "A New Estimate of Transaction Costs." The Review of Financial Studies 12 (5):1113-1141.

Lesmond, David A., Michael J. Schill, and Chunsheng Zhou. 2004. "The Illusory Nature of Momentum Profits." Journal of Financial Economics 71 (2):349 - 380.

Lettau, Martin, Matteo Maggiori, and Michael Weber. 2014. "Conditional Risk Premia in Currency Markets and Other Asset Classes." Journal of Financial Economics 114 (2):197 - 225. 
Lewellen, Jonathan, Stefan Nagel, and Jay Shanken. 2010. "A Skeptical Appraisal of Asset Pricing Tests." Journal of Financial Economics 96 (2):175 - 194.

Lou, Xiaoxia and Ronnie Sadka. 2016. Portfolio Construction, Measurement, and Efficiency: Essays in Honor of Jack Treynor, chap. Invisible Costs and Profitability. Springer, 135-153.

Nagel, Stefan. 2012. "Evaporating Liquidity." Review of Financial Studies 25 (7):2005-2039.

Newey, Whitney K. and Kenneth D. West. 1987. "A Simple, Positive Semi-Definite, Heteroskedasticity and Autocorrelation Consistent Covariance Matrix." Econometrica 55 (3):703-708.

Novy-Marx, Robert and Mihail Velikov. 2016. "A Taxonomy of Anomalies and Their Trading Costs." The Review of Financial Studies 29 (1):104-147.

Pastor, Lubos and Robert F. Stambaugh. 2003. "Liquidity Risk and Expected Stock Returns." Journal of Political Economy 111 (3):642-685.

. 2012. "On the Size of the Active Management Industry." Journal of Political Economy $120(4): 740-781$.

Pastor, Lubos, Robert F. Stambaugh, and Lucian A. Taylor. 2015. "Scale and Skill in Active Management." Journal of Financial Economics 116 (1):23 - 45.

Patton, Andrew J. and Allan Timmermann. 2010. "Monotonicity in asset returns: New tests with applications to the term structure, the CAPM, and portfolio sorts." Journal of Financial Economics 98 (3):605 - 625 .

Perold, Andre F. 1988. "The Implementation Shortfall: Paper Versus Reality." The Journal of Portfolio Management 14 (3):4-9.

Rosenbaum, Paul R. and Donald B. Rubin. 1984. "Reducing Bias in Observational Studies Using Subclassification on the Propensity Score." Journal of the American Statistical Association 79 (387):516-524.

Sadka, Ronnie. 2010. "Liquidity Risk and the Cross-Section of Hedge-Fund Returns." Journal of Financial Economics 98 (1):54 - 71.

Shleifer, Andrei and Robert W. Vishny. 1997. "The Limits of Arbitrage." The Journal of Finance $52(1): 35-55$.

Tibshirani, Robert. 1994. "Regression Shrinkage and Selection Via the Lasso." Journal of the Royal Statistical Society, Series B 58:267-288. 


\section{A. Mutual Fund Filters}

We filter our CRSP mutual fund database sample as follows. We first fill missing fund names using the nearest observation with a non-missing fund name within each CRSP fund number group. Of the 1,859,702 observations in the fund summary file, we assign fund names for 19,460 observations and remove 242 observations without recoverable names.

Share classes differ from one another in their fee structures, and we must account for this variation before aggregating across share classes within a fund. We convert net returns to gross returns by adding to net returns the annual expense ratio divided by 12, following Fama and French (2010). The fund summary file has missing or non-positive expense ratios for $16.9 \%$ of observations, however, and we take several steps to fill in the missing data. First, as before, we fill missing expense ratios with the nearest observation with a non-missing value within each CRSP fund number group. This operation reduces the number of missing expense ratios to $8.4 \%$ of the summary data. We then merge the monthly return data with the summary data by fund number and calendar quarter. This merge assigns expense ratios to $76.2 \%$ of fund-month observations. For unmerged observations, we merge again on fund number and year, where we take the average expense ratio within the fund number-year in the fund summary file. This operation boosts the number of fund-month observations with an expense ratio to $88.5 \%$ of the data or $5,774,820$ observations. We then drop the 89 observations with expense ratios exceeding $50 \%$ as these are almost certainly data errors.

Having accounted for the salient variation across share classes, we identify share class names of the same fund by extracting prefixes of CRSP fund names from the fund summary file. Suffixes represent different share classes of the same fund, e.g., "investor" and "admiral" shares of a Vanguard fund. We assign all funds with the same prefix to a unique fund group.

We take the following steps to obtain fund name prefixes. First, we cut off all fund names after a semicolon. Names after the semicolon are exclusively class names. We add to this dictionary of possible class names the Arabic and Roman numerals 1-10, letters A-Z, and a set of known share class markers, inv, inst, investor, institutional, trust, corp, advisor, admin, part, restricted, retail, shares, adv, common, series, prim, and primary. Although handling semicolons is straightforward, forward slashes - the other class-name delimiter used in CRSP - require more care. ${ }^{24}$ For example, fund names include "Franklin/Templeton" and "M/M" (money market), so "/" does not serve only as

\footnotetext{
${ }^{24}$ We deviate from Berk and van Binsbergen (2015)'s handling of fund subclasses because they do not properly handle forward slashes. From their page 9:

In most cases, the only difference among subclasses is the amount of expenses charged to investors, so simply including them as separate funds would artificially increase the statistical significance of any identified effect. For funds that appear in the CRSP database, identifying subclasses is a relatively easy process. CRSP provides a separator in the fund name in the form of either a colon ("6:") or a slash ("/"). Information after the separator denotes a subclass.

We attribute the difference between "colon" and "semicolon" to a minor database tweak or typographical error. The claim about forward slashes is incorrect because forward slashes often serve as abbreviations or concatenations rather than as delimiters, so we must devise new rules for separating out fund subclasses.
} 
a delimiter. As a preliminary step, we replace forward slashes in T/F, T/E, M/M, L/S, Long/Short, $\mathrm{S} / \mathrm{T}$, and $\mathrm{L} / \mathrm{T}$ with backslashes in fund names. Then we mark all fund names with a "/" for which (1) we have not already eliminated share classes under the semicolon rule and (2) the post-slash string is in the set of available suffixes. These are the set of funds with class information, and we clip the post-slash string for these elements. Finally we take the unique prefixes as our set of fund names sans class information. This mapping reduces the 61,734 surviving unique fund IDs in the CRSP monthly returns file to 33,538 unique fund groups. Of the $6,522,095$ observations in the monthly return file, only 4,298 of these are not assigned a fund group, and these observations are dropped.

We use fund names rather than CUSIP as our unique identifier to capture funds that have identical or near-identical investments but different CUSIPs or CRSP portfolio numbers. Fund names also have fewer missing values than either CUSIP ( $11.1 \%$ missing) or portfolio number (27.8\% missing) identifiers. This matching on name prefix also mimics the behavior of CRSP's Class Group code designed for this purpose, but which only becomes available in August 1998. For the observations for which class groups are defined, matching on name prefix gives 44,218 unique codes, whereas matching on both name prefix and class group gives 45,484 unique pairs. The overlap between methods is quite good despite the simplicity of our prefix approach.

Next we construct current and lagged total net asset (TNA) values for value-weighting fund returns within and across fund groups. In $9.2 \%$ of cases total net assets is undefined. We interpolate TNA values to avoid discarding such a large fraction of our data. Before interpolating we set to missing obvious data errors in which TNAs are recorded as negative or exceeding $\$ 1$ trillion USD. We linearly interpolate between non-missing log TNA values for each fund ID for which multiple TNA values are available (using the $\log (1+T N A)$ formulation to avoid infinite values). The filling procedure reduces the number of missing TNA values to $0.1 \%$ of the data. We then repeat or errorfiltering step and drop non-positive TNAs and TNAs exceeding $\$ 1$ trillion, which increases the number of missing values to $1.1 \%$ of the data. Lagging the TNA value by one month increases the share of missing observations to $2.1 \%$ of data.

We then filter out extreme return observations resulting from data errors. For example, we do not wish to include the recorded return of $533 \%$ on the Deutsche Equity 500 Index Fund in September 1997. Berk and van Binsbergen (2015) and Pastor, Stambaugh, and Taylor (2015) address these errors in part using external Bloomberg and Morningstar databases. We take a simpler approach to eliminate errors. We drop the 26 observations with reported returns exceeding one (i.e., $100 \%$ ) in absolute value. This approach is inspired by the shape of the tail of extreme returns in the data depicted in Figure A.I: the frequency of extreme returns decays roughly exponentially until $|r|=100 \%$, with a smattering of randomly spaced returns beyond this value. These observations appear to come from a different distribution, and for this reason, we classify them as likely errors.

Because our analysis concerns mutual funds, we filter out exchange-traded funds (ETFs), 
Figure A.I: Distribution of Log Fund Returns

Figure plots the distribution of the log of absolute monthly mutual fund returns. We truncate the plot to -1 on the left to maintain resolution on the extreme returns on the right. The dashed line represents of cutoff at $|r|=100 \%$.

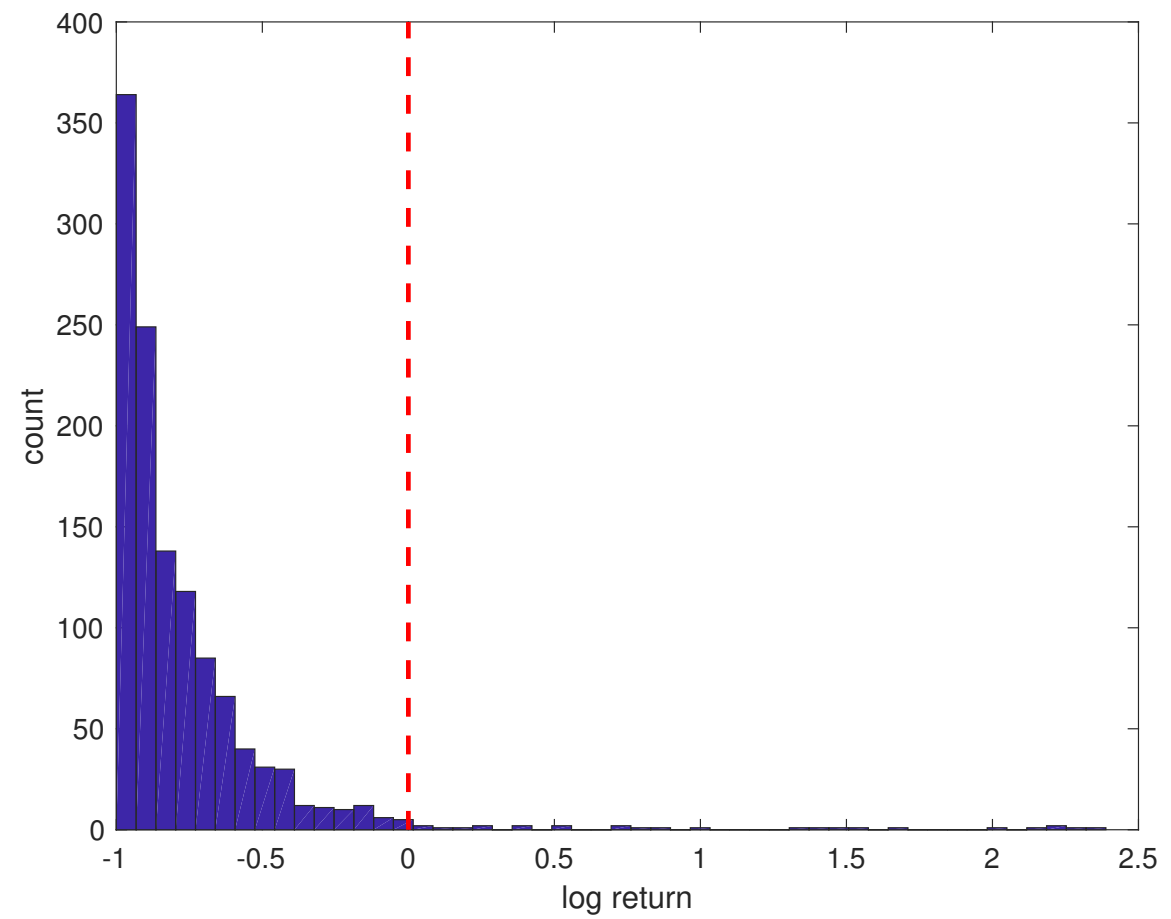

exchange-traded notes (ETNs), and variable annuity underlying (VAU) funds. To do this, we discard any observations for which et_flag indicates an ETF or ETN or vau_fund indicates a VAU at any time in a fund's life. These exclusions total $9.1 \%$ of observations.

We then construct fund group returns and total net assets by taking a weighted average of the returns and a sum of TNAs across component fund IDs. The return weights are one-month lagged TNAs. We retain observations for which the lagged TNA is undefined but the fund group only has one fund ID, that is, the one fund ID has an effective weight of $100 \%$. Fund group TNAs are the sum of current TNA values for all fund IDs for which the TNA is defined. Aggregating funds across share classes delivers 3,693,705 monthly fund-group observations.

As Fama and French (2010) note, "incubation bias arises because funds typically open to the public - and their pre-release returns are included in mutual fund databases - only if the returns turn out to be attractive." We follow their approach to countering incubation bias by keeping observations only after a fund group achieves a TNA of at least $\$ 10$ million (in December 2016 dollars). ${ }^{25}$ We retain data from funds that later drop below this threshold to avoid introducing

\footnotetext{
${ }^{25}$ Our inflation index is the Consumer Price Index for All Urban Consumers (CPIAUCSL) series provided by the Federal Reserve Bank of St. Louis' FRED database.
} 
a selection bias. Dropping fund groups that never achieve a $\$ 10$ million TNA eliminates $7.2 \%$ of fund group-month observations. Dropping observations from potential incubation periods before the $\$ 10$ million threshold is achieved eliminates another $8.9 \%$ of the sample.

Next, we filter fund groups based on fund name and objective. We first exclude all funds with names containing ETF, ETN, exchange-traded fund, exchange traded fund, exchange-traded note, exchange traded note, iShares, and PowerShares (not case sensitive) as a redundant filter on top of the CRSP-based ETF/ETN filter. These exclusions eliminate 10,779 observations. We then exclude any funds with names that have clear international or non-equity connotations: international, intl, bond, emerging, frontier, rate, fixed income, commodity, oil, gold, metal, world, global, China, Europe, Japan, real estate, absolute return, government, exchange, euro, India, Israel, treasury, Australia, Asia, pacific, money, cash, yield, U.K., UK, kingdom, municipal, Ireland, LIBOR, govt, obligation, money, cash, yield, $\mathrm{mm}, \mathrm{m} / \mathrm{m}$, diversified (but not diversified equity), and short term (not case sensitive). This filter complements our requirement that a fund have a domestic equity "ED" CRSP objective code. ${ }^{26}$ These filters reduce the number of valid funds from 22,509 to 7,334, and the corresponding number of non-missing return observations decreases to 1,085,108 for the entire December 1961 to December 2016 CRSP Mutual Fund Database.

Lastly, we restrict the set of funds to those with at least two years of monthly data in our 1970-2016 sample period. This filter reduces our sample to 7,320 mutual funds with 1,068,106 non-missing return observations. Summary statistics for this sample are reported in Table I.

\section{B. Bias of Symmetric Fama-MacBeth Regressions with General $h_{i t}$}

If instead we were to include the loadings on the liquidity proxies in Equation (2), the secondstage regression becomes

$$
r_{i t}=\sum_{k} \lambda_{k t} \hat{\beta}_{i k} 1_{i \in S}+\sum_{k} \lambda_{k t}^{M F} \hat{\beta}_{i k} 1_{i \in M F}+\sum_{l} \lambda_{l t} \hat{\gamma}_{i l} 1_{i \in S}+\sum_{l} \lambda_{l t}^{M F} \hat{\gamma}_{i l} 1_{i \in M F}+\epsilon_{i t} . t=1, \ldots, T
$$

From the conjectured return process of Equation (5), $\hat{\lambda}_{t}^{S}=\lambda_{t}^{S}, \hat{\lambda}_{k t}^{\Delta}=\bar{\eta}+\frac{\operatorname{cov}\left(\left(\eta_{i}-\bar{\eta}\right) \beta_{i}, \beta_{i}\right)}{\operatorname{var}\left(\beta_{i}\right)}$, and $\hat{\lambda}_{l t}^{\Delta}=\eta_{l t}$. The problem with this approach is that the $\hat{\lambda}_{l t}^{\Delta}$ term drops the time-varying part of $\eta_{i t}$, so we can no longer cleanly attribute time-varying costs to each return factor. Moreover the logic of mutual funds scaling down strategies in the face of high costs applies to $\eta_{i t}$ rather than to $\eta_{i}$.

To resolve the first issue we need to decompose $\eta_{s t}$ into factor-specific parts. The sum of all time-varying costs to factor investing using mutual funds is

$$
T V C_{i t} \equiv \sum_{l} \eta_{l t} \gamma_{i l}=\sum_{l} \eta_{l t}\left(\sum_{k} \gamma_{i k l} \beta_{i k}\right)
$$

\footnotetext{
${ }^{26}$ The CRSP objective code unifies Wiesenberger objective codes for 1962-1993 data, Strategic Insight objective codes for 1993-1998 data, and Lipper objective codes for 1998-2016 data.
} 
Regressing total time-varying costs on $\beta_{i}$ s decomposes costs into factor-specific time-varying parts,

$$
T V C_{i t}=\sum_{t} \sum_{k} \eta_{k t} \beta_{i k} 1_{t}+\epsilon_{i t}
$$

This regression can be interpreted as rotating the transaction cost space onto the return factor space. However, this rotation is imperfect because of cross-sectional variation in $\gamma_{i}$ s. To see why dispersion in $\gamma_{i}$ is problematic, consider a single coefficient estimate in a one-return factor case of Equation (15),

$$
\hat{\eta}_{t}=\frac{\operatorname{cov}\left(\sum_{l} \eta_{l t} \gamma_{i l}, \beta_{i}\right)}{\operatorname{cov}\left(\beta_{i}\right)}=\sum_{l} \eta_{l t} \bar{\gamma}_{l}+\sum_{s} \frac{\operatorname{cov}\left(\beta_{i} \eta_{l t}\left(\gamma_{i l}-\bar{\gamma}_{l}\right), \beta_{i}\right)}{\operatorname{cov}\left(\beta_{i}\right)}
$$

The first term represents the average exposure to liquidity or performance factors multiplied by the factors' time- $t$ realizations. This is the term of interest, but instead we identify this term plus a cross-sectional bias term. Focusing on the bias for each $l$, we might expect higher-than-average cost-factor sensitivities $\gamma_{i l}>\bar{\gamma}_{l}$ to be associated with lower betas if firms are risk averse. Although we would expect betas to be negatively associated with total costs per unit of risk exposure $\eta_{i t}$, it is not clear what relation the time-varying component alone should have with betas. Because of this ambiguous sign and the additional complexity of this approach, it is preferable not to include the liquidity exposures in the cross-sectional regression step.

\section{Match Quality Adjustments and Reporting for Matched Pairs}

\section{A. Bias Adjustment for Imperfect Matches}

Characteristics are not perfectly matched between stocks and mutual funds, and match characteristics may differ systematically between stocks and matched mutual funds. We follow Imbens and Rubin (2015)'s guidance to bias correct our matching estimator using a linear regression of outcomes on mutual fund ("control-group") attributes. ${ }^{27}$ For each date $t$, we bias-adjust mutual fund returns using a factor model for returns in which the estimated betas serve as risk exposures,

$$
r_{i t}=\alpha_{i}+\sum_{k} \delta_{k t} \hat{\beta}_{i k}+\epsilon_{i t}, i \in M F, t=1, \ldots, T
$$

Despite its matched pairs origin, Equation (17) is our usual Fama-MacBeth cross-sectional regression on the set of mutual funds.

Using Equation (17), we shift our estimate of mutual fund returns by the difference in betas

\footnotetext{
${ }^{27}$ Bias-correction is optional in univariate matches, but it considered to be best practice. It is required to correct for a "large-sample bias" for multivariate matches (Abadie and Imbens (2011)).
} 
between matched stocks and mutual funds multiplied by the time $t$ return to a unit of beta exposure,

$$
\frac{1}{3} \sum_{j \in \Omega(i)} \sum_{k} \delta_{k t}\left(\beta_{i k}^{S}-\beta_{j k}^{M F}\right),
$$

where $\Omega(i)$ denotes the three-element set of mutual funds matched to stock $i$. In effect, biascorrection marries the matched pairs approach with the factor model approach of Section IV. By contrast with the cross-sectional analysis of Section IV, however, these adjustments are "local" because differences in betas between stocks and matched mutual funds are small by construction.

\section{B. Evaluation of Match Quality}

Figure A.II plots the distribution of each matching variable $(\beta)$ for unmatched stocks, matched stocks, matched mutual funds, and all mutual funds. We see immediately that stocks have more variable factor exposures than mutual funds, so the most extreme stocks on either side of the beta distributions cannot be matched to mutual funds. Of stocks that are matched, their beta distributions line up well with those of mutual funds: there are no systematic biases at any point in the distribution of stock betas, as evidenced by the absence of over- and undershooting of the red line by the yellow-dashed line. Matching in the tails of the stock beta distributions is achieved by oversampling relatively extreme mutual funds. This feature manifests as a counterclockwise rotation of the purple quantile plot for all mutual funds to achieve the yellow-dashed quantile plot of matched mutual funds.

Table A.I quantifies match quality depicted in Figure A.II. All quintiles and factors have highly similar means and standard deviations between matched stocks $\left(S_{M}\right)$ and matched mutual funds $\left(S_{U}\right)$. All factors are matched well in quintiles one through four, and overall match percentages are high (81\%-93\%). Match quality deteriorates slightly in the most extreme quintiles, and particularly so in quintile five of market capitalization (the smallest stocks). Imperfect matching in the extreme quintiles also manifests in the imbalance between the number of matched stocks and matched mutual funds. For example, the typical matched mutual fund in the smallest stock group is used more than five times: $1,325,215$ stock-months are matched to three of 767,650 unique mutual fund-months.

The drawback to matching on a single variable is that other factors determining returns may differ wildly between stocks and matched mutual funds. Figure A.III confirms this issue by plotting bivariate distributions of four-factor betas when matches are constructed based only on $\beta_{M K T}$. Perfect matching between stocks and mutual funds would appear visually as complete coverage of the green regions by the red region. Instead we see green clouds surrounding the red region, indicating that matched mutual funds do not cover the same range of non-market betas as matched mutual funds. Focusing on the third column of the first row as an example, we see that matched stocks tend to have significantly larger $\beta_{S M B}$ than matched mutual funds, so the existence of a size premium would create a positive wedge between the returns on mutual funds and stocks. 


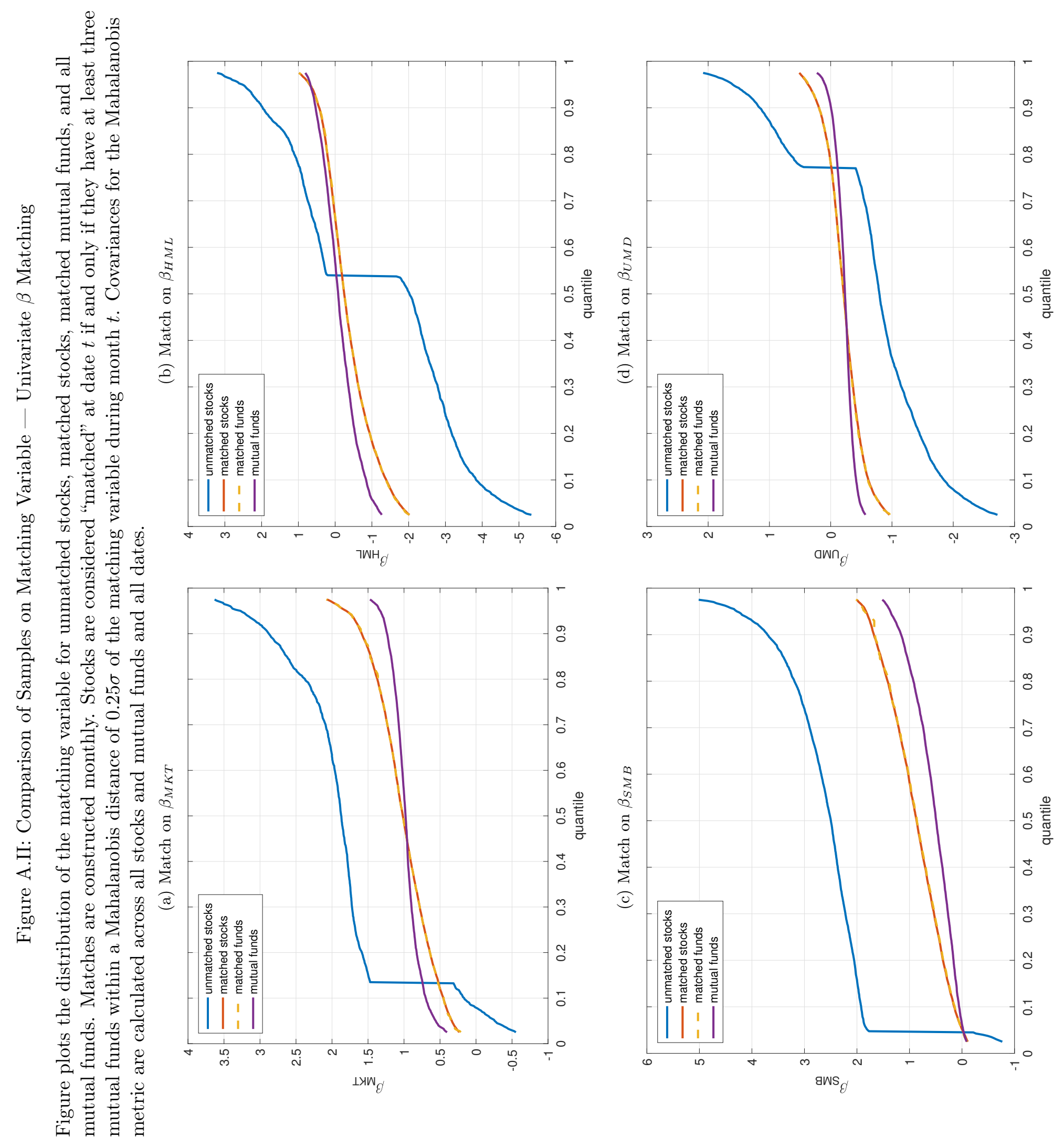




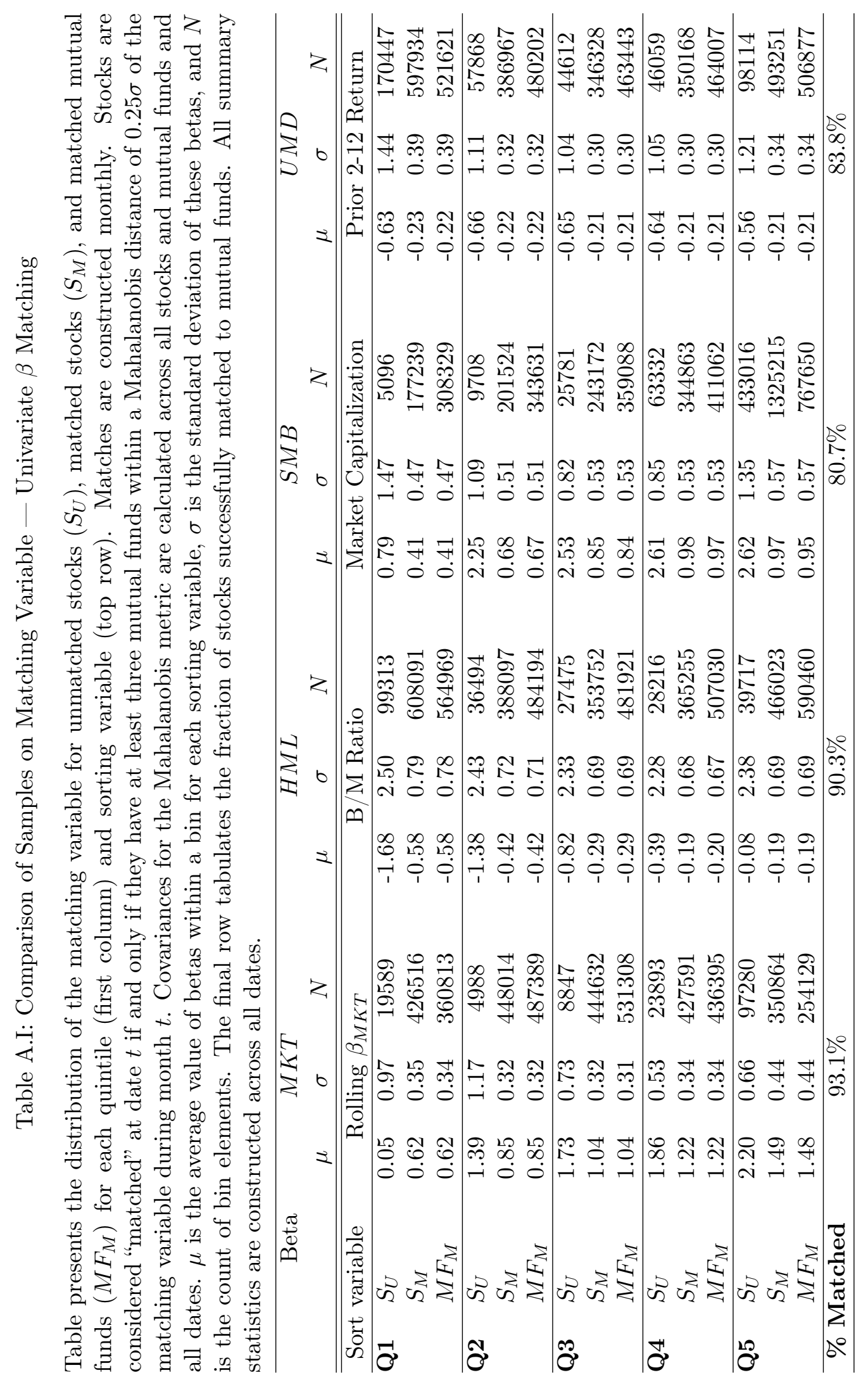


Figure A.III: Comparison of Samples on All Variables - Univariate $\beta$ Matching on $\beta_{M K T}$

Figure plots the distribution of factor betas for unmatched stocks, matched stocks, and matched mutual funds. Matches are constructed monthly using the single match variable $\beta_{M K T}$, and plots depict all bivariate distributions of Carhart (1997) four-factor betas. Stocks are considered "matched" at date $t$ if and only if they have at least three mutual funds within a Mahalanobis distance of $0.25 \sigma$ of the matching variable during month $t$. Covariances for the Mahalanobis metric are calculated across all stocks and mutual funds and all dates. To enhance visual clarity we clip the distribution of betas at the 2.5 and 97.5 percentiles and plot every 25 th data point for unmatched and matched stocks. We plot every 75 th data point for matched mutual funds because each matched stock has three associated mutual funds in its approximating set. Diagonal elements plot univariate histograms on a single beta rather than bivariate distributions.

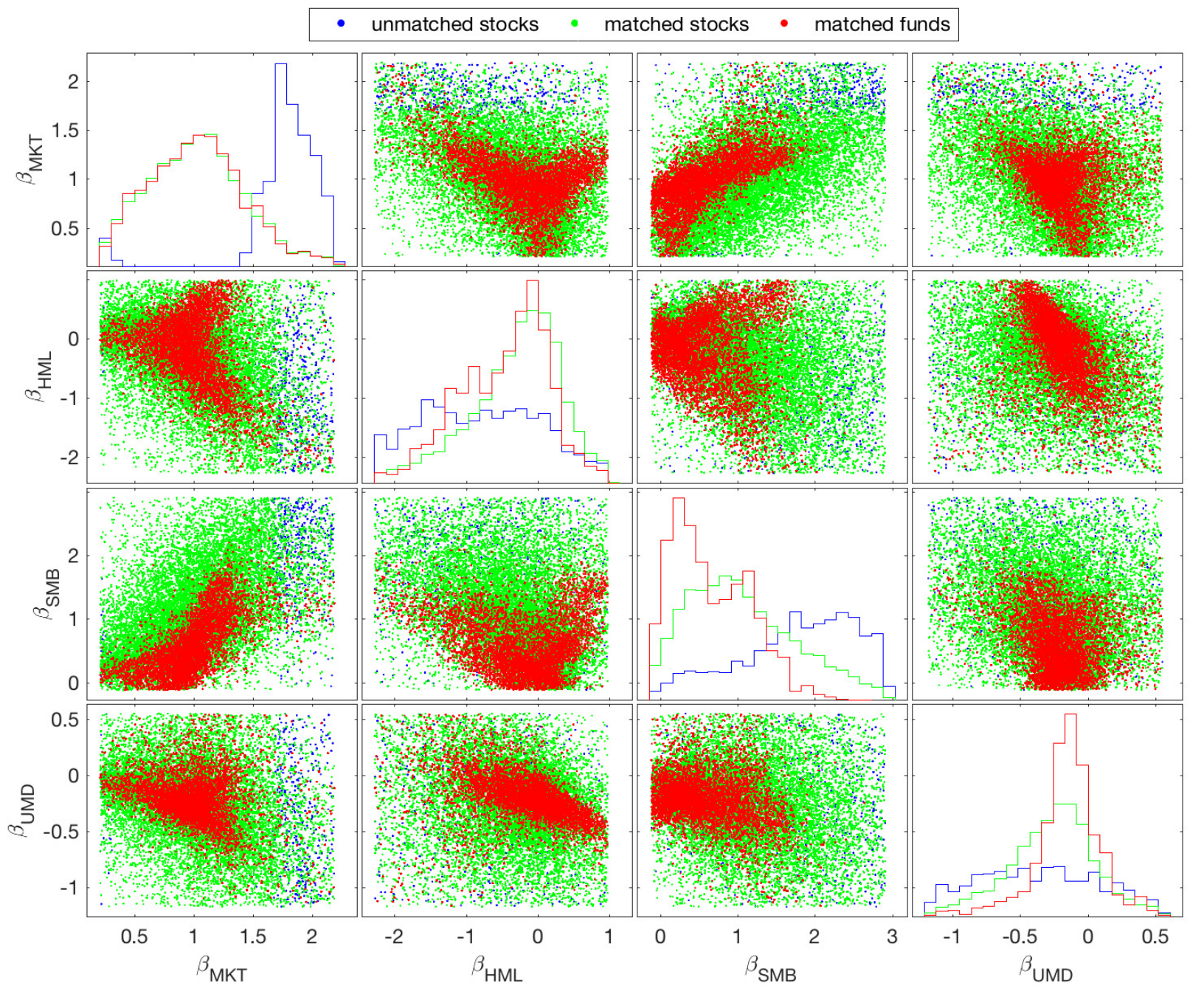




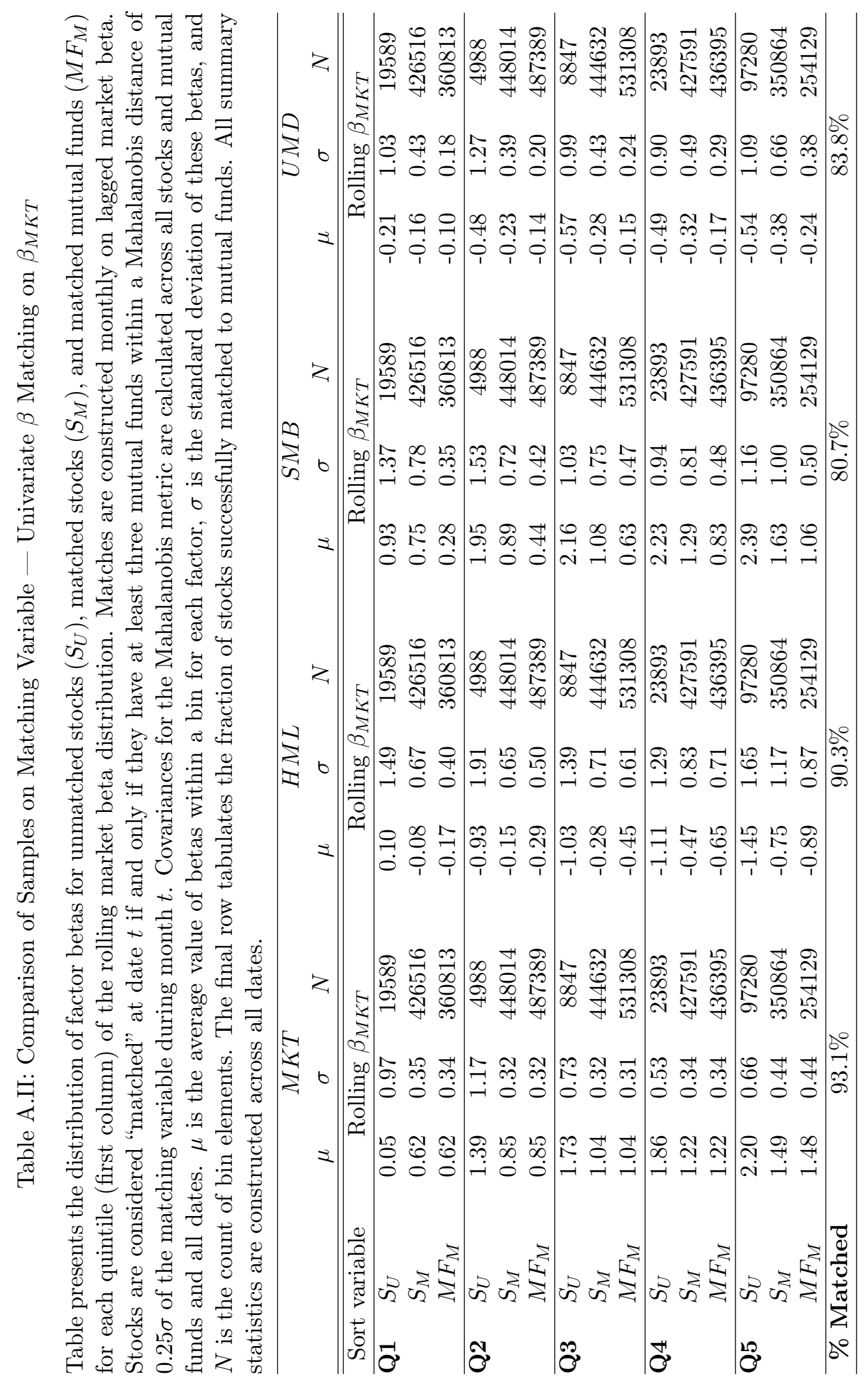


Table A.II quantifies these visual disparities. Taking the same $(1,3)$ coordinate, we see that the typical matched-stock size betas are consistently 0.3-0.5 larger for stocks than for mutual funds when entities are matched exclusively on market beta. Such differences are rife throughout the table. An apples-to-apples comparison of stocks and mutual funds thus requires multivariate matching if the true model of average returns has factors other than the market.

Figure A.IV and Table A.III report match quality when matching uses all four factor betas and a wider caliper of $1 \sigma$. The figure clarifies the trade-off between high multivariate match quality and sample coverage. The blue region of unmatched stocks is quite small in the univariate matches, but it visually dominates here. Likewise the matching along any single dimension is not quite as good as in Figure A.II, as the red and green regions of matched mutual funds and matched stocks do not perfectly coincide. However, these regions are much more similar than in the previous figure, and the differences between matched stock and matched mutual fund betas are small enough to be tamed by our local bias-adjustment methodology.

Table A.III quantifies this trade-off. Just over half of the sample is matched (the size of the blue region in Figure A.IV overstates the sparse-matching problem because the red and green regions are more densely populated). The distributions of matched stocks and matched mutual funds are mostly comparable, but they differ in the tails as more extreme stock betas are matched with less extreme mutual fund betas within our generous caliper. The table confirms the necessity of bias adjustment for this high-dimensional match. 
Figure A.IV: Comparison of Samples on All Variables — Multivariate $\beta$ Matching

Figure plots the distribution of factor betas for unmatched stocks, matched stocks, and matched mutual funds. Matches are constructed monthly using all Carhart (1997) four-factor betas, and plots depict all bivariate distributions of these betas. Stocks are considered "matched" at date $t$ if and only if they have at least three mutual funds within a Mahalanobis distance of $1 \sigma$ of the matching variables during month $t$. Covariances for the Mahalanobis metric are calculated across all stocks and mutual funds and all dates. To enhance visual clarity we clip the distribution of betas at the 2.5 and 97.5 percentiles and plot every 25 th data point for unmatched and matched stocks. We plot every 75 th data point for matched mutual funds because each matched stock has three associated mutual funds in its approximating set. Diagonal elements plot univariate histograms on a single beta rather than bivariate distributions.

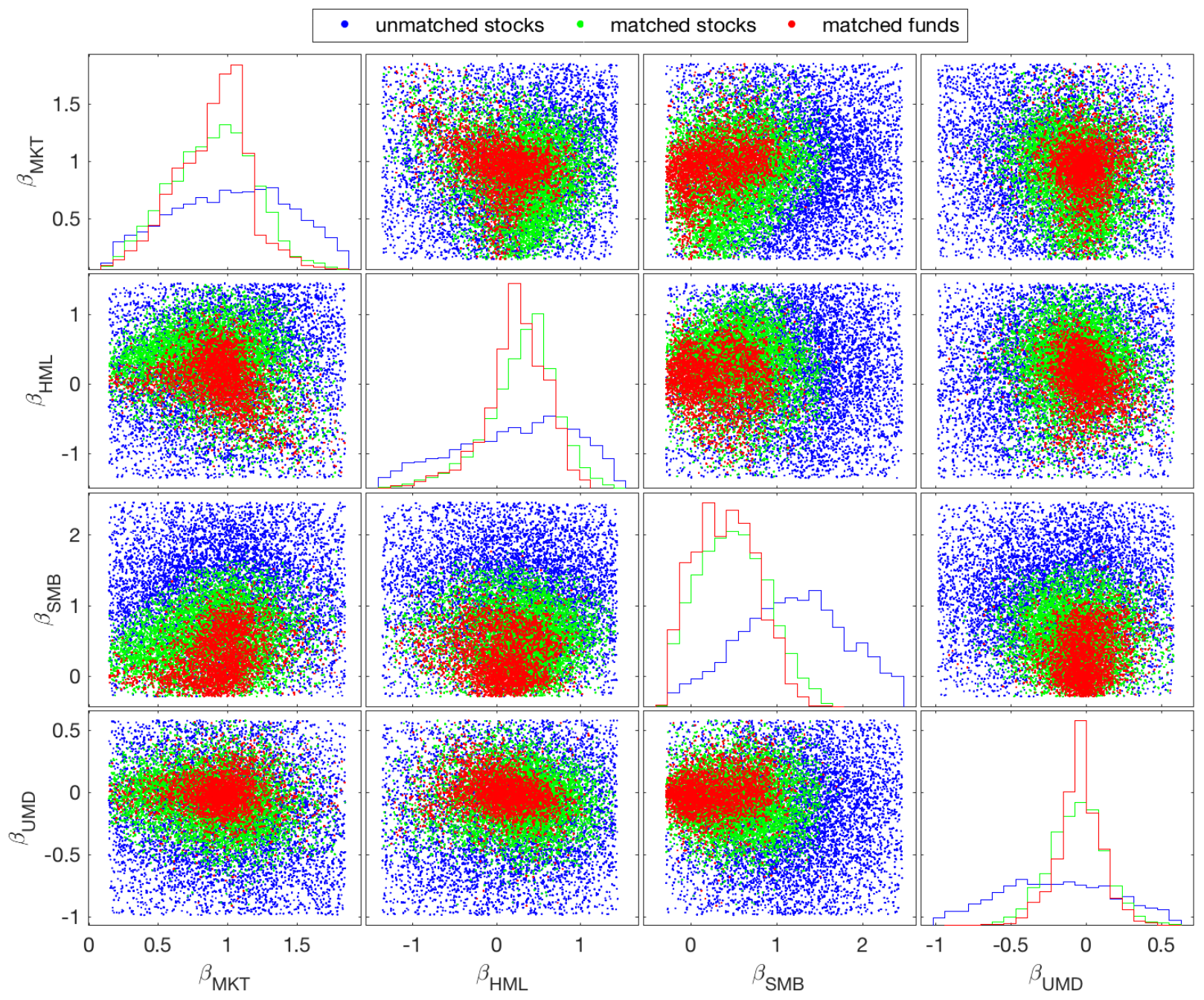




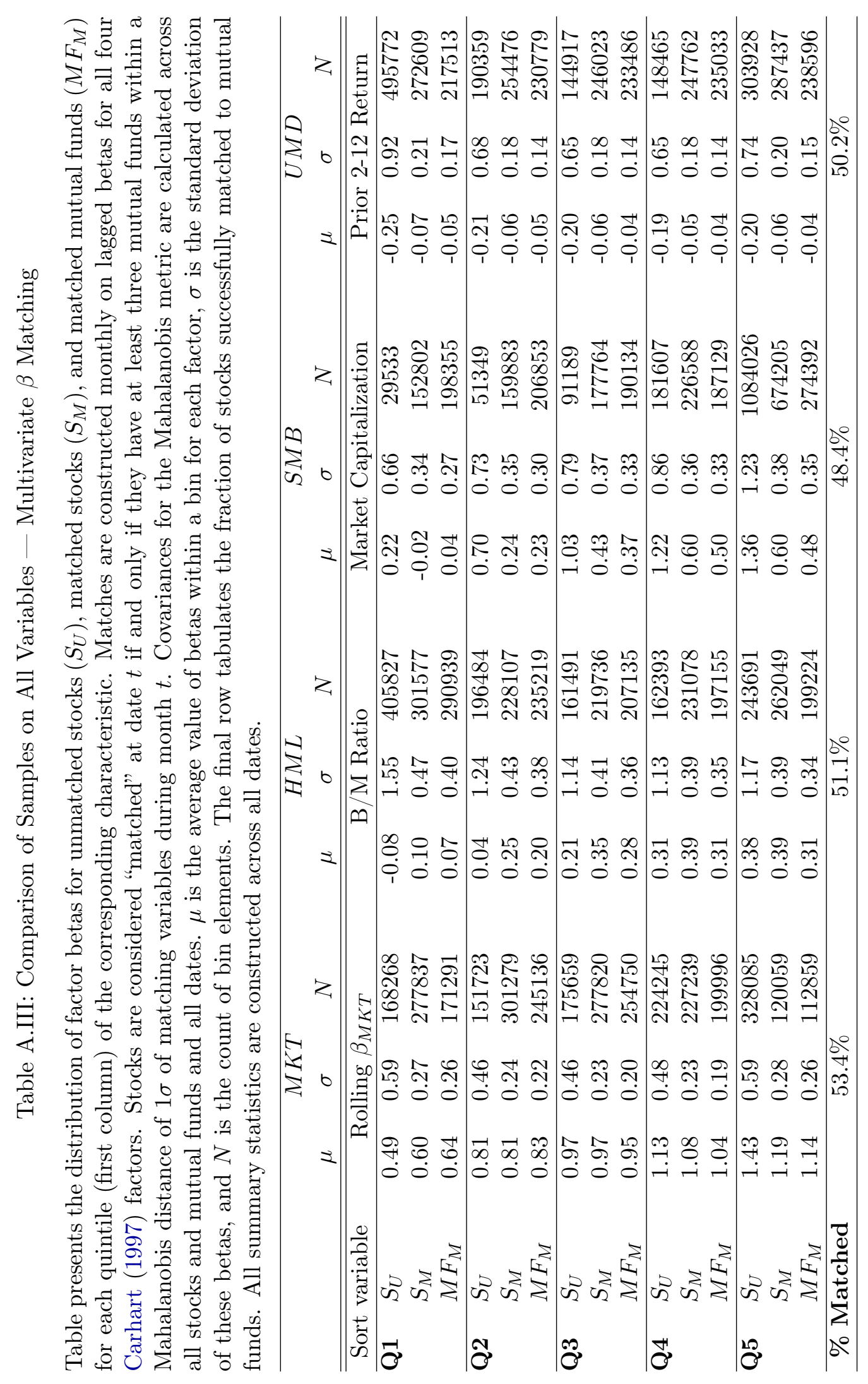

